Received 00th January 20xx, Accepted 00th January 20xx DOI: $10.1039 / \mathrm{x} 0 \mathrm{xx} 00000 \mathrm{x}$

\title{
Recent advances in iron-complexes as drug candidates for cancer therapy: reactivity, mechanism of action and metabolites
}

\author{
Mathilde Bouché, ${ }^{1 *}$ Cécilia Hognon, ${ }^{2}$ Stéphanie Grandemange, ${ }^{3}$ Antonio Monari, ${ }^{2}$ and Philippe C. \\ Gros. $^{1 *}$ \\ In this perspective, we discuss iron-complexes as drug candidates that are promising alternatives to conventional platinum- \\ based chemotherapies owing to their broad range of reactivities and to the targeting of different biological systems. \\ Breakthroughs in the comprehension of iron complexes' structure-activity relationship contributed to the clarification of \\ their metabolization pathways, sub-cellular localization and influence on iron homeostasis, while enlightening the primary \\ molecular targets of theses likely multi-targets metallodrugs. Both the antiproliferative activity and elevated safety index \\ observed among the family of iron complexes showed encouraging results as per their therapeutic potential and selectivity \\ also with the aim of reducing chemotherapy side-effects, and facilitated more pre-clinical investigations. The purpose of this \\ perspective is to summarize the recent advances that contributed in unveiling the intricate relationships between the \\ structural modifications on iron-complexes and their reactivity, cellular trafficking and global mechanisms of action to \\ broaden their use as anticancer drug and advance to clinical evaluation.
}

\section{Introduction}

The high therapeutic potential of platinum-based compounds against solid tumors has shed light on the inherent benefits of metal-based drug candidates in the fight against cancer. This is well exemplified by the prevalence of cisplatin in treatment regimens, where the latter is administered alone or in cotreatment with other chemotherapeutics or radiotherapy. ${ }^{1,2}$ Yet, the significant side effects of cisplatin, and the low survival improvement with platinum-based drugs impeded their advance to clinics, stimulating intense interest in finding alternative metals. $^{3,4}$ In this field, the cooperation of specialists at the interface between chemistry, biology, molecular imaging, bioinformatics and biophysics has enabled significant progress in the comprehension of the mechanism of action of metallodrugs. ${ }^{5,6,7,8,9,10}$ This contributes to accelerate the translation of lead candidates to clinical trials and emphasizes the bright future of metal complexes in cancer therapy.

Among transition metals, iron is a key player that is widely abundant in the biosphere and omnipresent in living systems. Moreover, this metal benefits a rich redox chemistry that grants access to a large scope of reactivities, making iron-based coordination complexes particularly attractive for biomedicine and especially for cancer treatment. However, uncovering their cellular targets and intricate modes of action is a complex task, further complicated by the presence of high levels of

${ }^{a}$. Université de Lorraine, CNRS, L2CM UMR 7053, F-54000 Nancy, France ${ }^{b}$. Université de Lorraine, CNRS, LPCT UMR 7019, F-54000 Nancy, France c. Université de Lorraine, CNRS, CRAN UMR 7039, F-54000 Nancy, France endogenous iron, and requires ingenious strategies to discriminate drug metabolites from the so called 'labile iron pool'. As a most illustrative example, significant progress in deciphering the cellular targets, modes of action and metabolites enabled ferroquine's advance to phase II clinical trial as a lead compound. This successful translation paved the way for in-depth studies of other molecular iron complexes, and for the rationalization of their modes of action and cellular trafficking. Moreover, the rise of sub-cellular chemical imaging, high-throughput analytical techniques and omics allowed the in-depth investigation of iron complexes' reactivity and metallomics at the cellular level. ${ }^{11,12,13}$

Furthermore, the progress in the comprehension of iron complexes' cellular reactivity has foreseen a rise in pre-clinical studies in view of advancing more candidates to clinical trial. This also confirms that investigating the intricate relationships between the structural modifications of iron complexes, and their reactivity, cellular trafficking and mechanisms of action is of paramount to allow proper translational approaches. For this reason, the present perspective is not intended to comprehensively detail the synthetic strategies to access ironcontaining complexes as this has been thoroughly covered in recent years, ${ }^{14,15,16}$ and we will rather focus on the structureactivity relationship of iron complexes as anticancer drug candidates and their effects at the cellular and body levels. While significant work on iron-containing polymetallic and heterobimetallic species, supramolecular coordination assemblies, and nanoformulations have advanced the field, those topics are not detailed herein and the reader is referred to recent thematic reviews for further detail. ${ }^{17,18}$ Differently from those approaches, we will focus on molecular iron complexes, the relationship between their structure, metabolization and 
antiproliferative activities. Efforts to characterize their molecular targets and mode of action using innovative techniques will be further discussed (Figure 1). Hence, we aim to provide a useful guidance for researchers willing to explore the mechanism of action of metallodrugs at the molecular level and further their pre-clinical evaluation. Meanwhile, we will also discuss the most important perspectives in the development of anticancer iron-complexes, providing a comprehensive vision that combines assessment of both their inherent chemical and biological effects, that is fundamental to develop novel and less toxic chemotherapeutic agents.

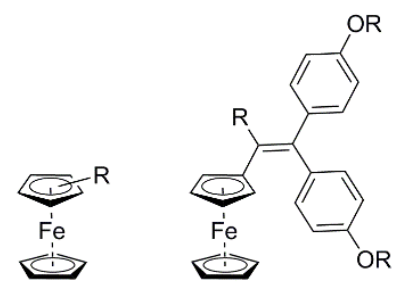

Ferrocenyls

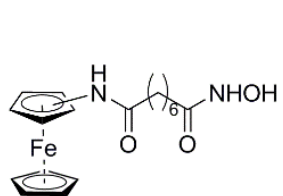

JAHA

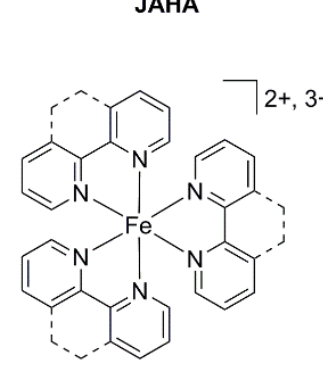

Iron-bpy/phen

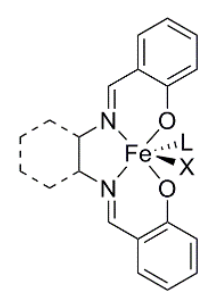

Iron-salen-/salophen$$
\text { Tron-salentsalophen }
$$
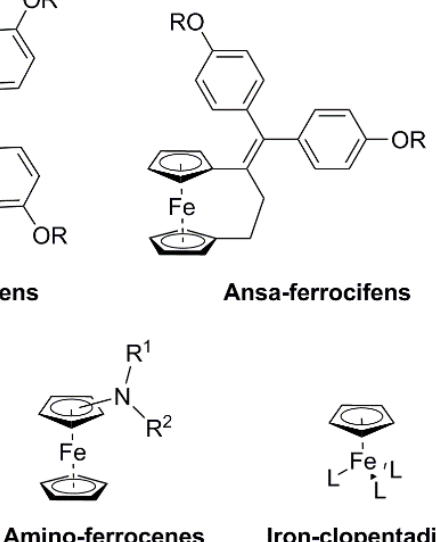

Ansa-ferrocifens

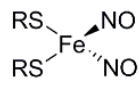

DNIC
Iron-TSC

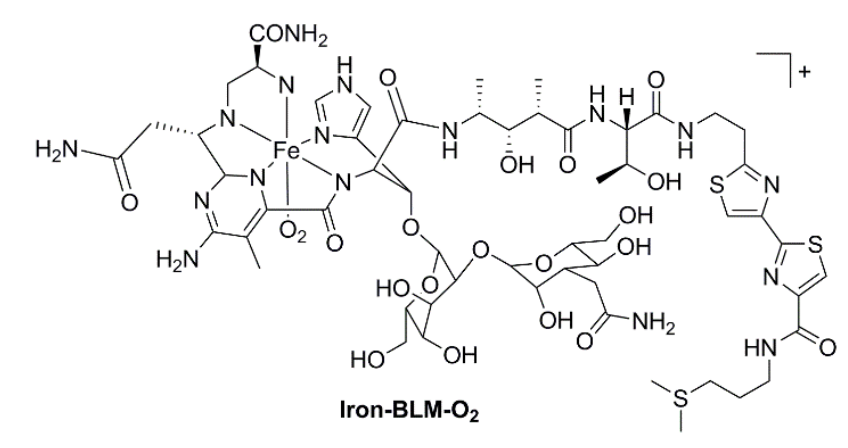

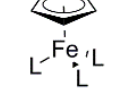

Iron-clopentadienyl

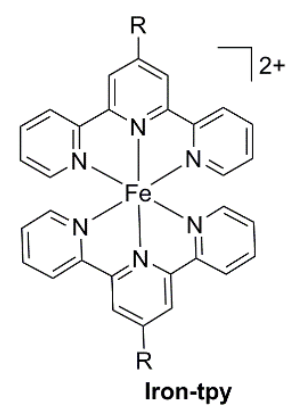

Figure 1. Iron complexes discussed in this review.

\section{Ferrocenyl Derivatives}

Ferrocene finds broad application in chemistry, and is a gold standard in electrochemistry due to its reversible one electron oxidation from +II to + III oxidation state, and high stability toward air and water. ${ }^{19}$ Its redox activity is also of interest for cancer treatment, due to its oxidation potential $(0.4 \mathrm{~V}$ versus standard hydrogen electrode) that enables its redox cycling in living systems. This can affect cancer cells by induction of oxidative stress, and motivated intense screening as anticancer candidates.

\section{Ferrocene-containing drug candidates}

Ferrocerone was firstly administered as treatment for irondeficiency anemia in the 1970s, although significant side effects prompted its interruption. ${ }^{20}$ Contrastingly, ferroquine is one of the most advanced metal-based therapeutic, undergoing phase II clinical trial against infectious diseases. This raised significant interest for analogues of ferroquine that display antimalarial properties ${ }^{21}$ and to repurpose them for anticancer research. $^{22}$

Overall, ferrocenyl-based drug candidates display antiproliferative activity at sub-millimolar concentrations against numerous cancer cell lines, including hormone dependent and independent breast cancers (MCF7 and MDAMB-231 respectively), cervical cancer (HeLa), lung cancer (A549), leukemia (CCRF-CEM, Jurkat) and so forth. Remarkably, most ferrocenyl complexes showed negligible effects on non-cancerous lines, hence displaying an elevated safety index that is beneficial in view of clinical evaluation. ${ }^{23,24}$ Ferrocenyl complexes showed redox activity that produces high levels of reactive oxygen species (ROS), notably by a Fentontype reaction. ${ }^{25}$ At low concentration ROS are key players in cell signaling and involved in the maintenance of cellular redox homeostasis. ${ }^{26}$ However, at elevated levels ROS provoke oxidative damages leading to apoptosis or senescence, thus offering alternative therapeutic mechanisms that can be effective in overcoming the acquired resistance of cancer cells towards DNA-binding drugs. ${ }^{27,28}$ Ferrocenes altered the cellular redox balance, ${ }^{29,30}$ triggered DNA oxidative damages and overall displayed a pro-apoptotic activity that induced cell cycle stop at the G2/M checkpoint following DNA replication. ${ }^{31,32}$ Ferrocene appended with hydroxyl-Schiff bases induced a G2/M arrest in HeLA cells while the Schiff base alone arrested cells in G1, emphasizing the effect of the ferrocene moiety in altering cancer cell cycle. ${ }^{33} \mathrm{~A}$ ferrocenyl-chromone complex induced about $60 \%$ arrest in G2/M phase in MCF7, HepG2 and CCRF-CEM, while the normal cell cycle could be recovered after exposure to a drug-free medium, possibly due to partial DNA repair in the absence of ferrocene. ${ }^{34}$ Contrastingly, 1ferrocenyl-2-(5-phenyl-1H-1,2,4-triazol-3-ylthio)ethanone stopped A549 cells at the G1-checkpoint, and the authors suggested a ROS mediated senescence induction through the p38 MAPK pathway. ${ }^{35}$ Ferrocenylseleno-dopamine derivatives induced G1 cell arrest on HepG2, stimulated the activation of caspases 3 and 9 while down regulating the anti-apoptotic Bcl-2 protein, and triggered cell apoptosis with partial necrosis. ${ }^{36}$ Of 
note, no significant differences in the cellular effects of two chiral isomers of ferrocene were observed on A549 and H322. ${ }^{37}$ Drug metabolites can be more active than their parent complexes, as illustrated by cisplatin, and their screening is of paramount importance. Ferroquine is metabolized by the hepatic microsomal systems via an oxidative route, leading mostly to the formation of mono- and $\mathrm{N}, \mathrm{N}$-demethyl ferroquine byproducts. ${ }^{38,39}$ Noteworthy, the kinetics were highly dependent on the microsomes' species, ranging from $80 \%$ oxidative metabolization in mice to less than $20 \%$ in human microsomes. Toxicology investigations highlighted the high in vivo tolerability of ferrocenium ions, ${ }^{40}$ with median lethal doses up to $\mathrm{LD}_{50}=440 \mathrm{mg} \cdot \mathrm{kg}^{-1}$ in $\mathrm{C} 57 \mathrm{BL} / 6$ mice, while a single I.P. injection of $0.2 \mathrm{mg} \cdot \mathrm{kg}^{-1}$ was sufficient to inhibit tumor growth, showing an elevated safety index. ${ }^{41}$

\section{Ferrocifens}

Taking advantage of the inherent redox activity of ferrocene in biological media and aiming at developing tailored and selective anticancer drug candidates, ferrocenes were conjugated to the estrogen receptor modulator, hydroxytamoxifen, that is currently used in clinical regimens. ${ }^{42}$ Such anticancer drug candidates, termed ferrocifens (Figure 1), efficiently inhibited the proliferation of a large range of cancers while showing negligible effects on non-cancerous cells, thus offering a beneficial safety index. Ferrocifens are especially promising for the treatment of hormone dependent breast cancer cells, such as MCF7 that does not respond to hydroxytamoxifen alone, via a mechanism of action involving the binding to estrogen receptors ER $\alpha$ and ER $\beta .{ }^{42}$ Such feature attracted considerable attention in the field and numerous ferrocifen derivatives were developed to fine-tune their pharmacological profiles and antiproliferative activities.

Remarkably, ferrocifens were overall found to have a cytostatic effect via senescence induction, ${ }^{42}$ as evidenced by characteristic morphological changes, overexpression of senescence markers, e.g. $\beta$-galactosidase $\left(\mathrm{SA}-\beta\right.$-gal) ${ }^{30} \quad$ pro-inflammatory interleukins and tumor necrosis factor TNF- $\alpha .{ }^{43}$ Hydroxyferrocifen induced cell accumulation in $\mathrm{S}$ phase and arrest in G0/G1 phase at longer time in MCF7 or ZR-75-1, while it permanently blocked MDA-MB-231 cells in $\mathrm{S}$ or G2/M phases. ${ }^{30}$ Tonolo et al. showed the relationship between structure, metabolization pathway and antiproliferative activity, exemplified by two isomeric ferrocifens that show dramatic changes in their metabolization and hence anticancer efficacy (Figure 2). ${ }^{44}$ Mimicking either enzymatic oxidation with $\mathrm{H}_{2} \mathrm{O}_{2}$ /horseradish peroxidase (HRP) or a chemical oxidation with $\mathrm{Ag}_{2} \mathrm{O}$, 1,1-bis(4'-hydroxyphenyl)-2-ferrocenyl-but-1-ene evolved via a metal-centered 2 e- oxidation to its quinone methide (QM) metabolite that can alkylate endogenous nucleophiles. ${ }^{44,45,46}$ On the other hand, the chemical oxidation of 1,2-bis(4'-hydroxyphenyl)-1-ferrocenyl-but-1-ene involved a metal-independent 1e- oxidation to diquinone methide that readily tautomerized to the phenol-quinone metabolite. ${ }^{44,47,48}$ The authors concluded that ferrocifens acted as prodrugs that could be redox activated to their QM active metabolites. $^{46}$
Thioredoxin reductase (TrxR) is a regulator of redox homeostasis overexpressed in numerous cancers, and a wellestablished target for some metallodrug candidates that bind to its selenocysteine residue and inhibit its biological activity. ${ }^{49,50}$ Both dimethylaminopropyloxyphenyl-ferrocifen and its QM metabolite significantly inhibited the cellular activity of TrxR, while hydroxyferrocifen showed a negligible effect. ${ }^{51}$ Remarkably, Tonolo et al. showed that a ferrocifen, whose mechanism of action was believed to occur via inhibition of TrxR and redox homeostasis disturbance, significantly accumulated in the mitochondria (35\% in MCF7) despite inducing only moderate decrease of the mitochondrial membrane potential. ${ }^{44}$ Hence, the authors suggested that the high drug accumulation in specific organelles did not necessarily correlate with the primary target responsible for their antiproliferative activity. Remarkably, direct DNA binding was rarely observed with ferrocenyl and ferrocifens, ${ }^{52,42}$ except when conjugated to DNA targeting moieties. ${ }^{53}$ This contrasts with the paradigm of metal based drug candidates that covalently bind DNA, and emphasizes the potential of ironbased drug candidates to display novel mechanisms of anticancer action that may provide opportunities for the treatment of cancers that are resistant to standard treatment.

A

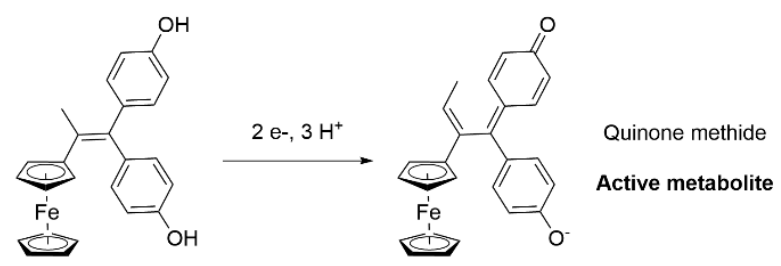

B $\mathrm{HO}$

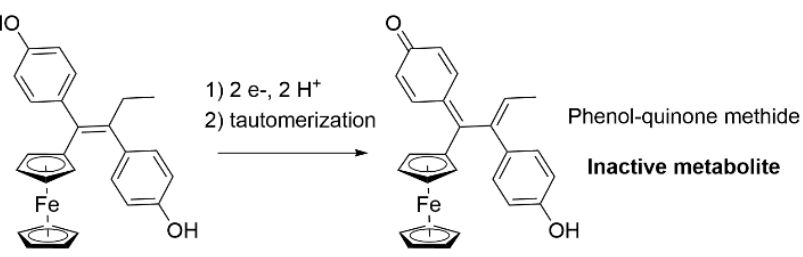

Figure 2. Pathways proposed for the metabolization of A) 1,1-bis(4'-hydroxyphenyl)-2ferrocenyl-but-1-ene into active QM, and B) 1,2-bis(4'-hydroxyphenyl)-1-ferrocenylbut-1-ene ( $\mathrm{Z}$ ) into inactive phenol-QM. Adapted with permission from reference 44 .

Investigation of the cellular trafficking of ferrocifens by optical imaging has been hampered by their low fluorescence quantum yield, ${ }^{54}$ and instead infra-red (IR) or Raman vibrational spectroscopies have been used tracking metal-carbonyl vibrations that are active in the $1850-2100 \mathrm{~cm}^{-1}$ range, where endogenous molecules are IR-inactive. ${ }^{5,56,57} \mathrm{~A}$ ferrocifen appended with rhenium-tricarbonyl tag enabled its quantification in MDA-MB-231 cells by IR and showed a dose dependent cellular accumulation that was supported by $\mathrm{Fe}$ and Re quantification using ICP-OES. ${ }^{58}$ Atomic force microscopy (AFM)-IR mapping at $1950 \mathrm{~cm}^{-1}$ showed the complex colocalization with both the nucleic acids phosphates stretching $\left(1080 \mathrm{~cm}^{-1}\right)$ and protein amid band $\left(1640 \mathrm{~cm}^{-1}\right)$ suggesting a predominant accumulation in the nucleus, although 
instrumental limitations precluded the mitochondria-nucleus discrimination.

The high hydrophobicity of ferrocifens lowers their anticancer activity and limits their direct pre-clinical evaluation on animal models. Several formulations were investigated to overcome this issue, using micelles or lipidic nanocapsules, achieving mixed results depending on the formulation used, the disease model and the administration strategy. ${ }^{59,60,61,62}$ However, ferrocenyl-hydroxytamoxifen and ansa-ferrocifen loaded in lipidic nanocarrier (65 $\mathrm{nm}$ diameter, $-4 \mathrm{mV}$ surface charge) administered by intravenous injection (45 mg.kg ${ }^{-1}$ ) to melanoma engrafted nude mice (SK-Mel28) successfully decreased the rate of tumor growth, and the ansa-ferrocifen showed a greater antiproliferative effect. ${ }^{63}$ This was attributed to its metabolization to QM and induction of dual pro-senescent and pro-apoptotic effects compared to ferrocenylhydroxytamoxifen that failed to generate the active metabolite. Surprisingly, ferrocifens incorporating ${ }^{18} \mathrm{~F}$ atoms that are active in PET imaging, ${ }^{74,64}$ are yet to be administered to living systems to track their in vivo biodistribution. However, such fundamental investigation, also dependent on medical imaging, should be expected to take place in the near future. Noteworthy, the start-up company Feroscan is pushing forward the preclinical investigation of nanoparticulate ferrocifens, ${ }^{20}$ and additional reports of in vivo testing of the most promising candidates is foreseen.

\section{JAHA}

Jay Amin hydroxamic acid, termed JAHA (Figure 1), are ferrocenes appended to the class I and II histone deacetylase (HDAC) inhibitor suberoylanilide hydroxamic acid (SAHA), an FDA approved agent for T-cell lymphomas treatment. ${ }^{65}$ HDAC inhibitors stimulated the expression of estrogen receptors that are deficient in triple negative breast cancer, for a dual therapeutic effect. JAHA exerted significant inhibition of HDAC of class I compared to its parent drug SAHA, although no activity was observed on class II HDAC. ${ }^{66}$ JAHA induced antiproliferative effects on both hormone-dependent and independent breast cancer cell lines, (MCF7 and MDA-MB-231 respectively) and induced MCF7 accumulation in the G2/M phase. ${ }^{67}$ Molecular docking on selenocyanide-JAHA suggested the binding of the ferrocene in the active site pocket of HDAC, favored by hydrogen bonding between the selenocyanide moiety and Y312 residue that does not occur with its parent drug. ${ }^{68}$ Its administration by oral gavage to $\mathrm{BALB} / \mathrm{c}$ mice showed a median lethal dose of $605.6 \mathrm{mg} . \mathrm{kg}^{-1}$ while both tumor inhibition and low systemic toxicity were observed at a 20 mg. $\mathrm{kg}^{-1}$ dose in MDA-MB-231 xenografted mice. However, further pre-clinical evaluation of JAHA derivatives is necessary to highlight their therapeutic potential, notably as prospective anti-lymphomas drug.

\section{Aminoferrocene-based activatable metallodrug candidate}

Aminoferrocenes (Figure 1) are relatively unstable species in aqueous media that readily degrade to free cyclopentadienyl and $\mathrm{Fe}^{2+}$ ions and can further catalyze ROS production. ${ }^{69,70,71}$
Their functionalization with a stimuli-responsive linker formed $\mathrm{N}$-alkylaminoferrocene prodrugs (Figure 1) that could be selectively activated to the unstable aminoferrocene. A ROSactivatable phenylboronic acid pinacol ester linker was used for tumor microenvironment targeted drug release, ${ }^{69}$ while photolabile derivatives of o-nitrophenyl were used to achieve light-triggered activation. ${ }^{72}$ Of note, some aminoferrocenes are highly lipophilic ( $\log p$ above 4 ), and aggregate in aqueous media, which limited both their degradation and ROS production. ${ }^{73}$ Pharmacokinetic profiling by radio-HPLC of Nalkylaminoferrocene incubated with human plasma or rat blood evidenced its rapid metabolization to ferrocenium. ${ }^{74}$ Reshetnikov et al. showed that a N-ferrocenyl-N-(1-alkyl1H1,2,3-triazol-4-yl)aminocarbonyloxymethylboronic acid pinacol ester bearing a fluorescent coumarin moiety was metabolized to a fluorescent $\mathrm{N}$-alkylaminoferrocene intermediate. ${ }^{75}$ Its trafficking in A2780 and NHDF cells (Normal Human Dermal Fibroblasts) highlighted its privileged accumulation in mitochondria and ROS mediated metabolization. On the other hand, conjugation of a fluorescent alkylated piperidine moiety to aminoferrocene showed the offon release of a fluorescent metabolite in lysosomes (Figure 3). ${ }^{76}$
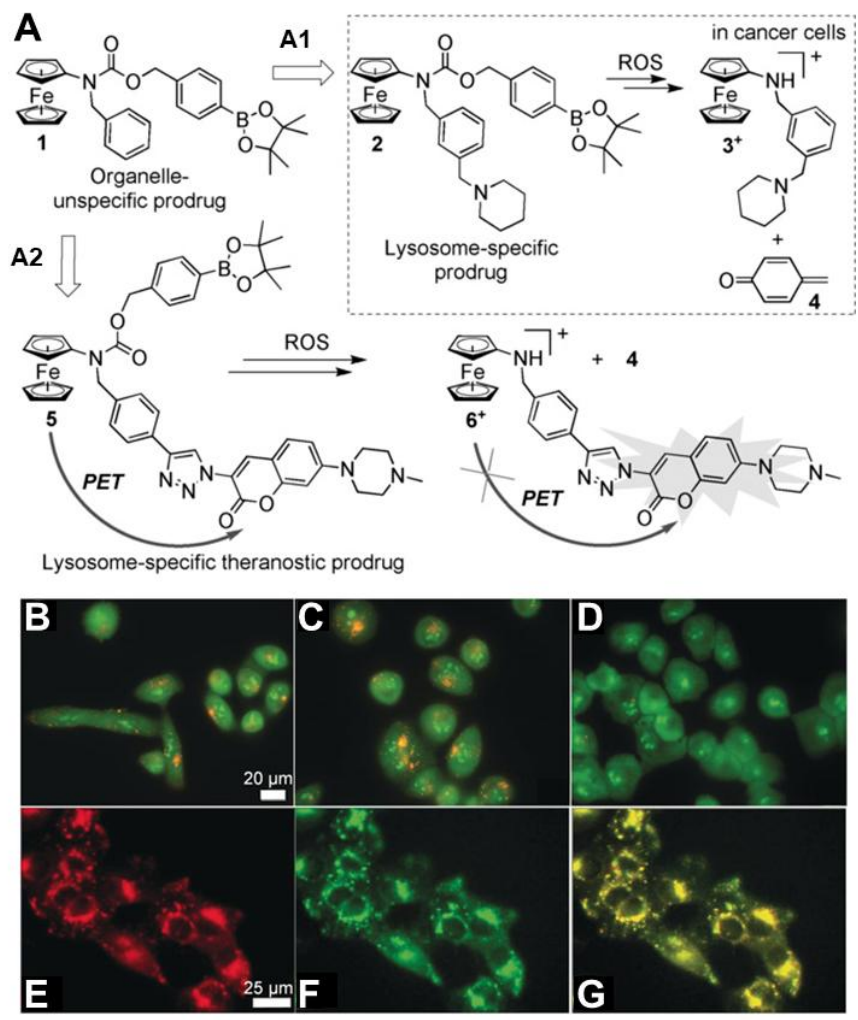

Figure 3. A) Structure of the aminoferrocene prodrugs 1, 2, 5 and their activation pathways $A 1$ and $A 2$ respectively to their photoinactive and fluorescent lysosome specific metabolites. Representative photographs of acridine orange stained DU-145 cells B) in drug-free medium, C) incubated with prodrug 1 or D) prodrug 2. DU-145 cells treated with prodrug 5 and Lysotracker Red under E) Lysotracker Red specific channel, F) channel specific of drug activation, $G$ ) overlap of (E) and (F). Adapted with permission from 76 . 
Ex-vivo exposure of liver slices to $\mathrm{N}$-alkylated aminoferrocene suggested its negligible effect on liver viability, which was supported by the absence of visible toxicity to BDF1 mice treated via intraperitoneal injection of up to $6 \mathrm{mg} . \mathrm{kg}^{-1}$ of drug. ${ }^{77}$ In L1210 inoculated BDF1 mice, its administration extended their survival by 17.5 days compared to 13.7 days for vehicle treated mice, and blood drawn L1210 cells showed both a disturbance in their mitochondrial function and enhanced levels of ROS. Further investigation of tailored Nalkylaminoferrocenes and activation by a broader range of stimuli is anticipated considering their potential for selective anticancer treatment in personalized medicine.

\section{Cyclopentadienyl-iron complexes}

Half-sandwich cyclopentadienyl-iron complexes (Figure 1) bear only one cyclopentadienyl ligand that can stabilize the metal by both electron-donor or acceptor effects, hence influencing the three additional coordination sites allowing a further fine-tuning of iron's reactivity. ${ }^{78}$ These compounds induce either necrosis or apoptosis depending on the ligands that complete the iron coordination sphere, although reports remain scarce and more biological testing are needed to conclude on their cellular effects. ${ }^{79,80}$ Of note, Cingolani et al. reported on the preliminary stability in aqueous medium and cellular effects of a cyclopentadienone containing iron complex at the oxidation degree $0,{ }^{81}$ which contrasts with the predominant iron(II/III)-based drug candidates. Undoubtedly, more progress in biological evaluation of such compounds should be achieved in the coming years.

\section{Polypyridyl-iron derivatives}

\section{Photoactive iron(III)-polypyridyl complexes}

Iron-polypyridyl complexes were investigated as an alternative to photo-active ruthenium-polypyridyl complexes that showed significant tumor growth control in vivo. ${ }^{82,83}$ The challenge to access photoactive iron-complexes for photochemotherapy (PC) and photodynamic therapy (PDT) also motivated significant interest in the field to overcome the early photobleaching or slow body clearance of FDA approved photosensitizers (PS). ${ }^{84,85}$

Chakravarty et al. showed the potential of iron(III) complexes to display photoactivity under red-light irradiation when bearing tripodal polypyridyl ligands such dipyridoquinoxalines $(\mathrm{dpq}),{ }^{86}$ dipicolylamines $(\mathrm{dpa}),{ }^{87,88}$ and Schiff base derivatives. ${ }^{89}$ Appending an anthracenyl to $\mathrm{Fe}(\mathrm{III})$ dipicolylamine complex had a dual effect by shifting the ligand-to-metal charge-transfer (LMCT) band to the near IR window, while allowing its intercalation in DNA. ${ }^{87,88}$ This favored its cellular accumulation in the nucleus which resulted in the significant production of hydroxyl radicals $\left({ }^{\bullet} \mathrm{OH}\right)$ and DNA cleavage after light irradiation. ${ }^{\circ} \mathrm{OH}$ was predominantly produced while only negligible levels of other ROS such as singlet oxygen $\left({ }^{1} \mathrm{O}_{2}\right)$ were observed among $\mathrm{Fe}(\mathrm{II})$-dpq analogs. ${ }^{86}$ Functionalization of $\mathrm{Fe}(\mathrm{III})$-dpa complex with pyrene showed DNA intercalation, preferred accumulation in the nucleus of HeLa cells, and a light-triggered pro-apoptotic activity. ${ }^{90}$ On the other hand, triphenylphosphonium appended $\mathrm{Fe}$ (III)-dpa complex targeted mitochondria, disrupted their activity and induced cell death. ${ }^{91}$ Remarkably, functionalization of a polypyridyl-Fe(III) complex with a naturally occurring coumarin enabled the access to an LMCT based photoactivatable complex, hence enabling its intracellular tracking in the mitochondria under red-light. ${ }^{92}$ Conjugating a BODIPY photosensitizer to Fe(III)-dpa significantly enhanced its antiproliferative activity on HeLa cells from $\mathrm{IC}_{50}=75 \mu \mathrm{M}$ to $\mathrm{IC}_{50}=2 \mu \mathrm{M}$ under visible or red light irradiation $(600-720 \mathrm{~nm})$, and localized in mitochondria due to the BODIPY moiety. ${ }^{93}$ Its in vivo effects were evaluated on BT474 (human breast adenocarcinoma) xenografted nude mice that received $5 \mathrm{mg} . \mathrm{kg}$ ${ }^{1}$ dose of iron complex, followed by photo-irradiation. Although tumor growth measurements indicated enhanced inhibitory effect of the iron-containing drug candidate compared to vehicle, negligible effects of the infra-red photo-activation were observed, an event attributed to the low photoconversion under infra-red light. ${ }^{94}$ Remarkably, a Fe(III)-dpa-BODIPY analog bearing a vitamin B6 ligand displayed enhanced antiproliferative activity toward MCF7 and HeLa cells, preferential accumulation in lysosome rather than mitochondria, and enhanced uptake by the vitamin B6 channels. ${ }^{95}$ Biotin-functionalization of a Fe(III)-phenanthroline (phen) complex did not affect its in vitro antiproliferative activity although it hindered its intercalation in DNA, suggesting a mechanism of action independent of DNAbinding. ${ }^{96}$ Cellular trafficking of the biotin-Fe(III) conjugate was comparable to the free biotin and diverged from the nontargeted Fe(III)-phen complex, showing an uptake mechanism mainly by receptor mediated endocytosis and partial diffusion pathway, cytosolic localization at $3 \mathrm{~h}$ incubation and nucleus translocation after $12 \mathrm{~h}$ incubation.

\section{Bipyridyl- and phenanthroline-iron(II) complexes}

Contrastingly to $\mathrm{Fe}(\mathrm{III})$ complexes, $\mathrm{Fe}(\mathrm{II})$-polypyridyl are poorly emissive with a short-lived excited states, due to the ultrafast deactivation of the photophysically active metal-toligand charge-transfer $\left({ }^{3} \mathrm{MLCT}\right)$ state to the dark metal-centered ${ }^{3} \mathrm{MC}$ and ${ }^{5} \mathrm{MC}$ states. Hence, their use as photosensitizers and tracking their localization by optical techniques is challenging. However, significant success has been achieved recently in increasing the fluorescence lifetime by producing $\mathrm{Fe}(\mathrm{II})$ complexes displaying low energy MLCT band and increasing the ${ }^{3}$ MLCT- ${ }^{3}$ MC gap. ${ }^{97,98}$ Gasser et al. reported on a $\mathrm{Fe}(\mathrm{II})-$ phen complex and its hydrophilic analog bearing $\mathrm{SO}_{3}{ }^{-}$moieties, both showing comparable photophysical properties despite a poor singlet oxygen production $\left({ }^{1} \mathrm{O}_{2}\right.$ yields $<1 \%$ in PBS) and limited improvement in light-triggered cell cytotoxicity, which were associated to the short life-time of the excited state. ${ }^{99}$ However, both complexes were stable in human plasma, exhibited low photobleaching and the hydrophilic Fe(II)-phen complex showed reduced dark cytotoxicity compared to its lipophilic analog. Extension of the $\pi$-system of phen ligands with $-\mathrm{OMe}$ or $-\mathrm{NMe}_{2}$ terminating moieties red-shifted the optical absorption of their corresponding $\mathrm{Fe}(\mathrm{II})$-phen 
complexes up to $708 \mathrm{~nm}$, although negligible cytotoxicities and low luminescence quantum yields $(<0.1 \%)$ were correlated with poor ${ }^{1} \mathrm{O}_{2}$ production. ${ }^{100}$ Of note, their counter ion exchange from $\mathrm{PF}_{6}^{-}$to $\mathrm{Cl}^{-}$efficiently enhanced their water solubility but showed no effect on photophysical properties and cytotoxicity, hence emphasizing the access to long-lived photoactive state in $\mathrm{Fe}$ (II) complexes as a key issue in determining their phototoxicity.

Che et al. highlighted the impact of the coordination sphere onto the mechanism of action of two Fe(II) complexes bearing rigid quinquepyridine (qqy) or flexible 2,6-bis[hydroxybis(2pyridyl)methyl]pyridine $\left(\mathrm{py}_{5}-\mathrm{OH}\right)$ pentadentate ligands showing high antiproliferative activity on a range of cancer cell lines $\left(\mathrm{IC}_{50}\right.$ values in the range of $0.8-3.1 \mu \mathrm{M}$ or $0.6-3.4 \mu \mathrm{M}$ respectively), although the $\mathrm{Fe}(\mathrm{II})-\left(\mathrm{py}_{5}-\mathrm{OH}\right)$ complex showed a reduced cytotoxicity toward CCD-19Lu cells (normal lung fibroblast). ${ }^{101,102}$ While both complexes induced DNA damage, pro-apoptotic activity and regulated the MAPK proliferation signaling pathway, in depth study of their DNA cleavage ability, ROS production, genes and pathways regulation highlighted profound mechanistic differences. Fe(II)-qqy complex produced elevated levels of ROS, cleaved DNA and arrested HeLa cells in S phase independently from p53, while $\mathrm{Fe}(\mathrm{II})-\left(\mathrm{py}_{5}-\mathrm{OH}\right)$ complex produced ROS by a Fenton reaction that arrested HeLa cells in G0/G1 phase by activation of p38 and p53 pathways. Both complexes regulated different genes expression, although similarities with a known drug, ciclopirox, suggested a mechanism involving the regulation of iron levels. Of note, a $\mathrm{Fe}(\mathrm{II})-\left(\mathrm{py}_{5}-\mathrm{OH}\right)$ analog displayed SOD-like activity which could contribute to its antiproliferative effect. ${ }^{103}$

A range of $\mathrm{Fe}(\mathrm{II})$-bipyridine (bpy) and $\mathrm{Fe}(\mathrm{II})$-phenanthroline (phen) complexes (Figure 1) with increasing planarity were synthesized and showed increased lipophilicity and uptake by HeLa, MCF7 and A375. ${ }^{104}$ After accumulation in the cellular membrane $\mathrm{Fe}(\mathrm{II})$-bpy was internalized by a transferrinmediated cellular uptake, and translocated to the nucleus at $24 \mathrm{~h}$ after accumulation in the lysosomes and diffusion the cytoplasm. Its cellular localization may also be correlated to its biological effects as $\mathrm{Fe}(\mathrm{II})$-bpy scavenged intracellular ROS, induced cell cycle arrest in $\mathrm{S}$ phase via a down regulation of CDK2 and CyclinA, and triggered significant DNA damages and p53-mediated apoptosis. Contrastingly, $\mathrm{Fe}(\mathrm{II})$-phen neither accumulated in the nucleus nor caused DNA damage despite its comparable mechanism of uptake. It scavenged ROS, induced G0/G1 cell arrest, and inhibited the AKT pathway. Those examples also highlight the fine interplay between iron complexes and the cellular machinery. Indeed, while high concentration of iron usually triggers oxidative stress production, some complexes may reduce it by ROS scavenging. The different mechanism of action between Fe(II)-bpy and $\mathrm{Fe}(\mathrm{II})$-phen was suggested to relate to a threshold in lipophilicity that could direct their cellular trafficking (Figure 4). ${ }^{104}$ The hydrophilic $\mathrm{Fe}(\mathrm{II})$ complex of 2- selenoimidazole[4,5- f]1,10- phenanthroline showed both enhanced pro-apoptotic activity and anti-angiogenic activity on HUVEC cells by inhibiting VEGF and the AKT pathway, decreasing the neovascularization of Chick embryo chorioallantoic membranes (CAM). ${ }^{105} \mathrm{Fe}(\mathrm{II})$-phen complexes also sensitized U87 cells (glioblastome) to TNF- related apoptosis- inducing ligand (TRAIL) and synergized to induce a pro-apoptotic activity involving p38 and p53 activation. ${ }^{106}$

In addition, $\mathrm{Fe}(\mathrm{II})$-phen complexes were stable for $48 \mathrm{~h}$ toward both glutathione (GSH) and bovine serum albumin (BSA), and penetrated cells primarily by a transferrin receptor (TfR) mediated endocytic pathway. ${ }^{107}$ They scavenged ROS in Caski cells in a dose dependent manner, which contrasts with most iron complexes. Both the morphological changes of the cell and accumulation in subG1 phase suggested a pro-apoptotic activity. Negligible changes in the hematological analysis of blood lipid, liver and kidney function or pathological investigation of major organs were observed in vivo. Intravenous injection of $\mathrm{Fe}$ (II)-phen to U87 xenografted nude mice significantly inhibited tumor growth by a pro-apoptotic mechanism through ROS overproduction, while showing negligible systemic toxicity. ${ }^{106} \mathrm{Fe}$ (II)-phen synergized with cisplatin in the treatment of esophageal squamous cell carcinoma (ESCC) due to its cellular transport via TfR that is overexpressed in ESCC. ${ }^{108}$ Its greater in vitro safety index compared to cisplatin ( 2.7 vs. 1.4$)$ is reflected by its low side effects on kidney, lungs, neurons and hematology of BALB/C mice. ${ }^{109}$ Therefore, in view of their elevated translational potential, more pre-clinical investigation are anticipated in the near future to accelerate their progression to clinical trial evaluation.
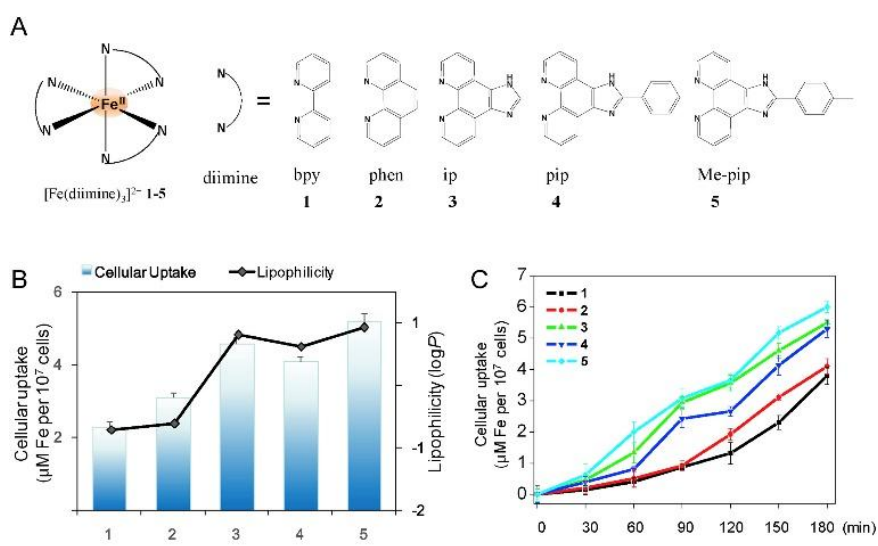

D
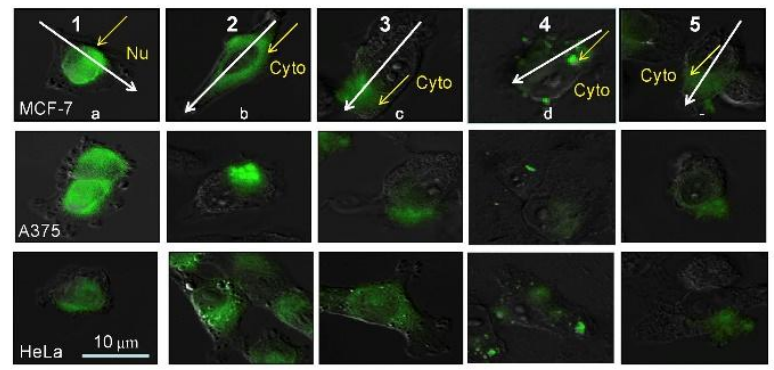

$\mathrm{E}$
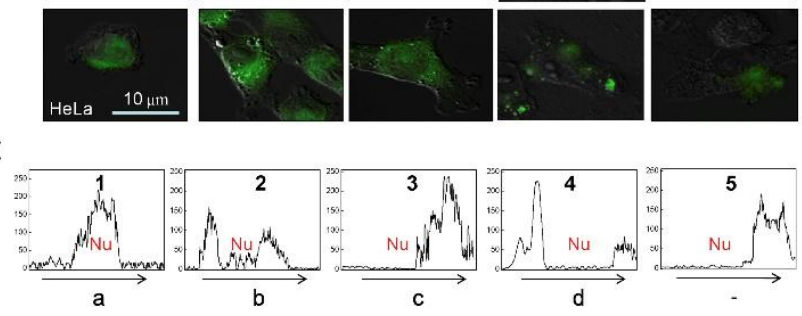
Figure 4. A) Structure of the selected $\mathrm{Fe}(\mathrm{II})$-bpy/-phen complexes. B) Relationship between structure, lipophilicity and cellular uptake in MCF7 cells incubated with the complexes for $3 \mathrm{~h}$ or $\mathrm{C}$ ) followed at several times points over $3 \mathrm{~h}$. D) Representative photographs showing the localization of the complexes by fluorescence in MCF7 (top), A375 (middle) and HeLa (bottom) cells, and E) Evolution of the fluorescence intensity across the cells. Adapted with permission from reference 104

\section{Terpyridyl-iron complexes}

Fe(II)-terpyridine (tpy) complexes (Figure 1) are also characterized by poor photoactivity. ${ }^{110}$ Their functionalization with anthracene or pyrene showed a moderate ligand centered fluorescence, although no MLCT luminescence was observed due to the unfavorable competition with lower energy MC states and rapid non-radiative decay. For the same reasons the phenyl-functionalized complex showed no photoactivity. ${ }^{111}$ $\mathrm{Fe}(\mathrm{II})$-tpy complexes partially intercalated into DNA, however, because of their non-radiative deactivation, their ${ }^{1} \mathrm{O}_{2}$ production was negligible, and they rather cleaved DNA by ${ }^{\circ} \mathrm{OH}$ production under green light, hence inhibiting HeLa proliferation. The complexes localized primarily in the nucleus of HeLa cells which contrasts with the cytoplasmic diffusion of the free ligand, and emphasized the iron-related effect on both the cellular trafficking and light induced activity.

Remarkably, Gattuso et al. combined insights from molecular modeling and simulation, spectroscopy, and cellular biology to investigate the effects of phenyl- or pyridyl- functionalization of Fe(II)-tpy complexes on their interaction modes with DNA and their subsequent cellular effects (Figure 5). ${ }^{112}$ A $14 \mathrm{bp}$ model B-DNA composed of poly(dA)-poly(dT) and poly(dC)poly $(\mathrm{dG})$ was used to investigate by classical all-atoms molecular dynamic simulations three interaction modes, e.g. major groove binding, minor groove binding and intercalation.
A

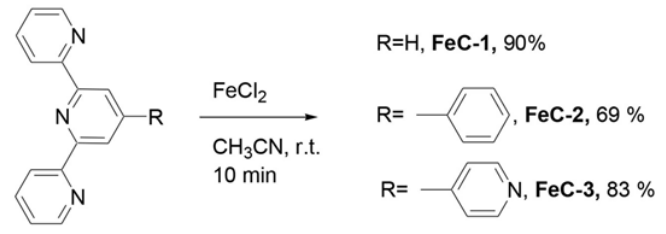

B
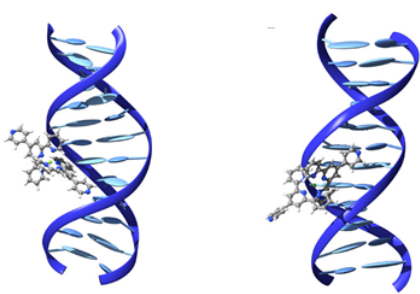

MinGB

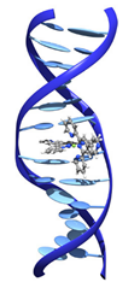

MajGB

$\operatorname{poly}(\mathrm{dA})-\operatorname{poly}(\mathrm{dT})$

poly(dG)-poly(dC)

\begin{tabular}{llll} 
C & & poly(dA)-poly(dT) & poly(dG)-poly(dC) \\
\hline FeC-1 & MajGB & Unstable & Unstable \\
& MinGB & $\begin{array}{l}\text { Stable (Diffuses in } \\
\text { the Groove) } \\
\text { Unstable }\end{array}$ & $\begin{array}{l}\text { Stable (Diffuses in } \\
\text { the Groove) } \\
\text { Unstable (Evolves } \\
\text { toward MinGB) }\end{array}$ \\
\hline Int & MajBG & Unstable & Unstable \\
& MinGB & Stable & Stable \\
& Int & Stable & Stable \\
\hline FeC-3 & MajGB & Metastable (10 ns) & Metastable (10 ns) \\
& MinGB & Stable & Stable \\
& Int & Stable & Stable
\end{tabular}

Figure 5. A) Synthesis of the three Fe(II)-tpy complexes of interest, B) representative examples of the interaction of $\mathrm{FeC}-3$ with DNA obtained by molecular dynamic, i.e. major groove binding (left), minor groove binding (middle) and intercalation (right). C) Table summarizing the DNA interaction mode of the three Fe(II)-tpy complexes. Adapted with permission from 112

While persistent minor groove bindings were obtained for all the Fe(II)-tpy complexes, the presence of a pendant phenyl- and pyridyl- moiety induced the formation of a stable intercalation mode. The presence of the pendant moieties also significantly limited the diffusion of the complex in the DNA minor groove as compared to their unfunctionalized analog, while no persistent interaction was observed in the major groove. Of note, the analysis of the non-covalent interaction pathways revealed the formation of a hydrogen bond between the pyridylsubstituent of the $\mathrm{Fe}(\mathrm{II})$-tpy complex with the electron rich amine moiety of guanine. Minor groove binding and intercalation of both $\mathrm{Fe}$ (II)-tpy complexes significantly bended DNA, and showed a partial eviction of the guanine from the ideal B-DNA stacking. While contribution from molecular modeling to elucidating the molecular mechanism of action of iron-based drug candidates is scarce, this example illustrates the significant progress of simulation techniques in providing an atomistic resolution of the interactions taking place at the molecular level between the drug candidates and their biomolecular targets. Such comprehension will certainly prove fundamental in view of designing tailored drugs, and hence more important breakthroughs are expected in the near 
future $^{113,114}$ to rationalize the interaction with DNA or protein targets, oxidative stress induction and drug internalization pathways either via passive lipid membrane permeation or by interaction with cellular transporters.

\section{Salen- and salophen-iron derivatives}

Iron complexes bearing $\mathrm{N}, \mathrm{N}$-bis(salicylidene)ethylenediamine (salen) or N,N-bis(salicylidene)phenylenediamine (salophen) ligands (Figure 1), mimic the catalytic activity of the iron active sites of enzymes such as the cytochrome P450, dioxygenase and so forth. ${ }^{115,116}$ Although they showed low interaction with DNA, ${ }^{117}$ their $[\mathrm{Fe}(\text { salen })]^{+}$metabolite interacted via electrostatic interaction with phosphates of the DNA backbone, ${ }^{118}$ which is beneficial for iron-mediated production of ROS, oxidative DNA cleavage and elevated antiproliferative activity. ${ }^{119}$ Moreover, the Fe-salophen complex remained stable over $3.5 \mathrm{~h}$ in physiological conditions while rapid conversion was observed in acidic conditions. ${ }^{120}$

Those complexes displayed high antiproliferative activity, $\mathrm{IC}_{50}$ as low as $58 \mathrm{nM}$ were observed on A2780 cells for the phenyltetrazole analog of Fe-salophen complex. ${ }^{121}$ Negligible effect on healthy cells, notably skin fibroblast, human hepatocytes and primary lung were evidenced. ${ }^{122}$ On platinumresistant ovarian cancer cells, Fe-salophen complexes induced chromatin fragmentation, activation of caspases 3, 8, 9 and PARP cleavage (Figure 6). ${ }^{122}$ SMS-KCNR NB cells treated with $\mathrm{Fe}$-salophen complex featured a more pronounced ROS production than the ones exposed to the free ligand, DNA degradation and cell cycle arrest in G1 phase. ${ }^{123}$ In depth investigation also showed disruption of mitochondria's membrane, stimulation of caspases 3,7 and regulation of proliferation signaling pathways (MAPK and JNK) due to treatment with Fe-salophen. Surprisingly, while a dose of $3 \mu \mathrm{M}$ significantly decreased the viability of HUVEC cells, doses in the range of $0.3-1 \mu \mathrm{M}$ stimulated their proliferation, showing dose-dependent effects. Noteworthy, Gust et al. suggested that Fe-salophen complexes inhibit cell proliferation via interconnected necroptosis and ferroptosis pathways, which should receive more attention in the future. ${ }^{124,125}$ Repeated IP administration of $\mathrm{Fe}$-salophen to albino rats showed overall negligible effect in vivo, although cases of hepatocyte degeneration and pulmonary mononuclear cell infiltrates that are characteristic of inflammation, were observed at elevated drug doses. ${ }^{122}$ Remarkably, a Fe-salophen was magnetically active, hence enabling its use for hyperthemia on VX2 xenografted rabbits after intra-arterial administration, and paving the way for alternative combination therapies. ${ }^{126}$

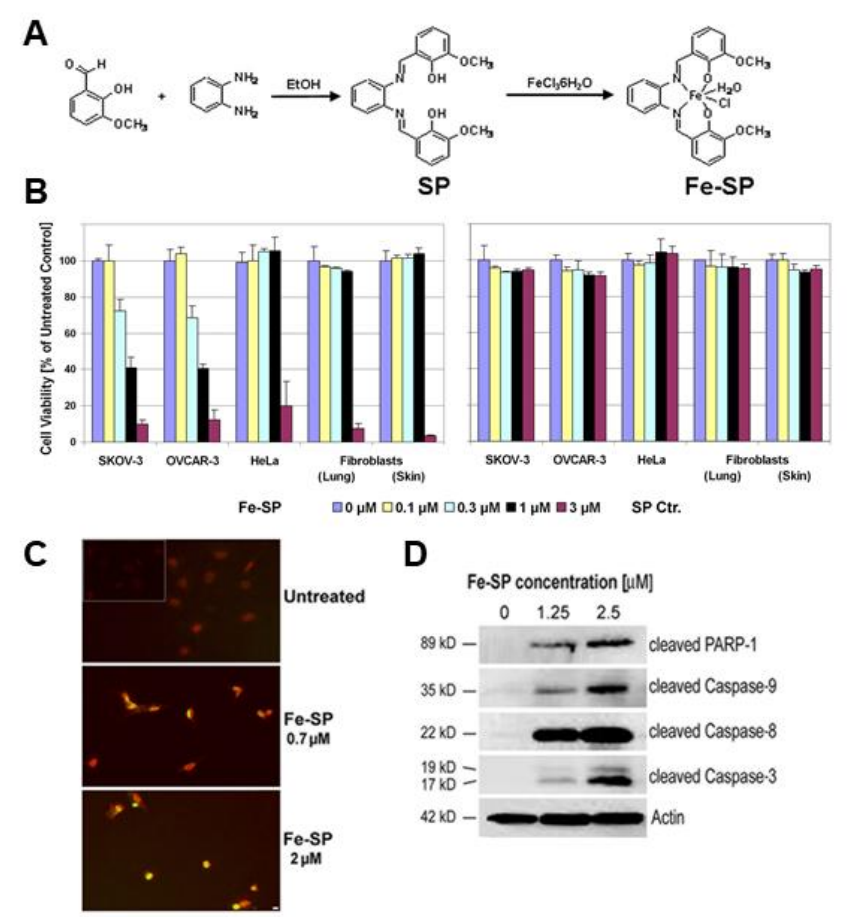

Figure 6. A) Synthesis of Fe-salophen complex, and its effect in SKOV-3 on B) the cell viability, C) DNA adducts by TUNNEL assay and D) expression of caspase 9, 8, 3 and PARP-1. Adapted with permission from 122.

\section{Thiosemicarbazone-iron derivatives}

Iron overload has been identified as a pro-tumoral factor, in part due to the enhanced need for nutrients and oxygen of highly proliferative cancer cells. ${ }^{127}$ Hence thiosemicarbazones (TSC) were developed to target excess iron in cancer cells and chelate the "labile iron pool" (LIP) to, on one hand prevent its association to hemoglobin, ferritin and so forth to limit cancer cell proliferation, and on the other hand induce local antiproliferative activity due to the formation of toxic iron-TSC complexes. The reader is referred to compelling reviews for further details concerning their structure-activity relationship. ${ }^{128,129,130}$ TSC, e.g. triapine, di-2-pyridylketone 4,4dimethyl-3-thiosemicarbazone and so forth, formed stable complexes with iron (Figure 1) that could regulate iron homeostasis by both direct chelation of the LIP and inhibition of iron transporters. Moreover, those iron complexes displayed additional antiproliferative activity by producing high levels of ROS, damage DNA and induced G1/S cell arrest. ${ }^{131,132,133,134}$ Remarkably, triapine and its iron complex behave differently in CT-26 (colon cancer) xenografted mice, the iron complex bound proteins and was excreted via the urines to a larger extent than the free ligand. ${ }^{135}$ This fact was also correlated with the different pharmacological properties of the ligand and its complex that direct their cellular trafficking (Figure 7). ${ }^{135}$ Although iron-TSC complexes are stable toward bioreducing agents, e.g. GSH and metalothioneins, ${ }^{136}$ they engage numerous 
targets, notably by inhibition of ribonucleotide reductase that is involved in DNA synthesis. ${ }^{137}$ The complexes inhibited the p21 gene and cyclins $\mathrm{D}$, which contributed to cell cycle regulation, while they upregulated anti-oncogenes such as $\mathrm{N}$-myc. ${ }^{138,139,140}$ Tracking the chelation of the radionuclide ${ }^{59} \mathrm{Fe}$ by TSC suggested the TSC-mediated inhibition of Fe-transferrin adducts, while showing negligible effect toward $\mathrm{Fe}-\mathrm{S}$ cluster proteins that are involved in balancing the redox homeostasis and gene regulation. ${ }^{128}$ Triapine advanced to phase II clinical trials and showed encouraging anti-leukemia effects despite limited efficacy on solid tumors, and significant side effects including vomiting and anemia, ${ }^{141,142}$ foreseeing more upcoming pre-clinical evaluation of TSC analogs.

A
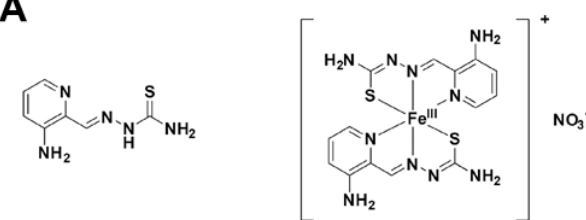

B

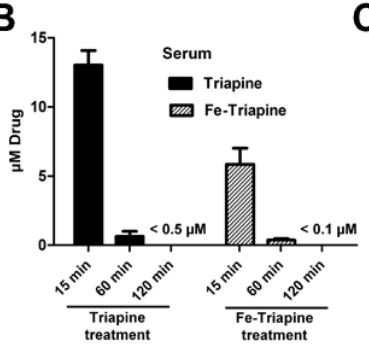

C

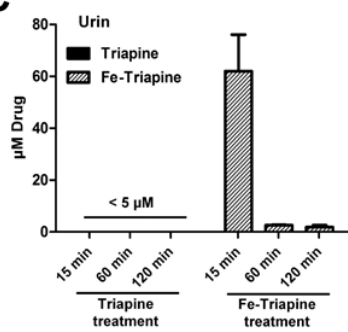

D

E
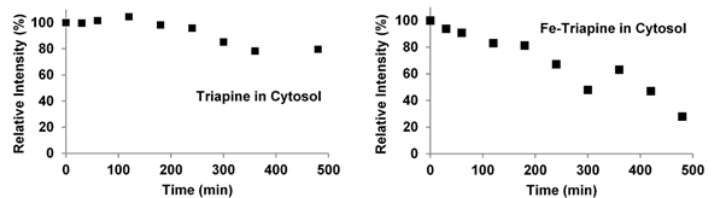

Figure 7. A) Structure of triapine and its iron complex, comparison of their biodistribution in B) serum and C) urin. Evolution of the cytosolic levels of D) triapine and E) Fe-triapine complex. Adapted with permission from 135.

\section{Bio-inspired iron complexes}

A variety of bio-mimic ligands and natural extracts are efficient iron chelators, i.e. flavonoids, rosins, salinomycin and so forth, ${ }^{143,144,145}$ and offer alternative therapeutic strategies displaying overall elevated biocompatibility. Among them, bleomycin (BLM), a glycoprotein that possesses both a DNA interaction domain and metal binding domain, showed high therapeutic potential against a variety of cancers. Indeed, its coordination to $\mathrm{Fe}^{2+}$ ion and activation of $\mathrm{O}_{2}$ (Figure 1) led to DNA cleavage, preferentially at GC and GT sequences. ${ }^{146,147} \mathrm{~A}$ squared pyramidal low spin BLM-Fe(III)-OOH intermediate was suggested to trigger $\mathrm{H}^{\prime}$ ' atom transfer from the $\mathrm{C} 4$ cytosine of DNA to the metal, ${ }^{148,149}$ which contrasts from hemelike chemistry that occurs in enzymes such as cytochrome P450 and deoxygenases, ${ }^{150}$ although the exact mechanism of action remains debated (Figure 8). ${ }^{151}$ BLM displayed high antiproliferative activity against a range of cancer cells, and stopped cell cycle in both G2 and mitosis. BLM successfully completed phase IV clinical trial in combination to electroporation techniques, i.e. lipid membrane's permeabilization by application of an electric field, to overcome its limited spontaneous uptake. It is currently commercialized under the brand name of Blenoxane ${ }^{\circledR}$ for the treatment of various cancers, despite limitations inherent to its systemic toxicity. ${ }^{152,153}$ Its metabolization was linked to bleomycin hydrolases, and BLM showed predominant excretion through the kidneys with up to $65 \%$ of the injected drug detected in the urines after $24 \mathrm{~h}$. Consequently, screening for BLM derivatives and overall bio-mimetic iron chelates is required for increasing its safety index and pharmacokinetics.
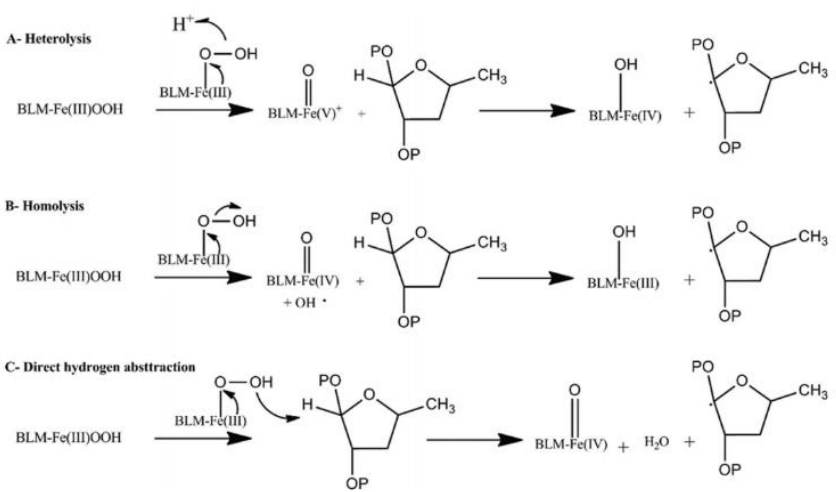

Figure 8. Reactivity and intermediates hypothesized for BLM-iron interaction with the C4' cytosine. Adapted with permission from 151.

\section{Iron-nitrosyl complexes for NO delivery}

Iron is a key player in the biosynthesis and transport of nitric oxide (NO), a signaling molecule that contributes to programed cell death at high concentrations. ${ }^{154}$ Hence, biomimetic iron complexes were developed to grant intracellular NO delivery and inhibit cancer cell proliferation by both enhancing the activity of p53 gene, and suppressing the activity of key reparation protein of mammals, the O6-methyl-guanineDNAmethyl-transferase 2 and mitochondrial respiration. ${ }^{155,156}$ Iron complexes delivering NO were recently reviewed, ${ }^{157,158}$ which highlighted the therapeutic potential of nitrosylation of $\mathrm{Fe} / \mathrm{S}$ clusters to afford tetrahedral dinitrosyl iron complexes $\left[\mathrm{Fe}(\mathrm{NO})_{2}\right]$ (DNIC) (Figure 1) that release NO under various light or redox stimuli and ligand substitution. ${ }^{159,160,161}$ DNIC showed promising anti-proliferative and pro-apoptotic activities in the micromolar range, ${ }^{162,163,164}$ notably acting via inhibition of survival associated proteins and activation of JNK proliferation signaling pathway. ${ }^{165}$ Finetuning the coordination sphere to stabilize the Fe-NO bond ${ }^{166}$ enabled NO delivery with half-lives in the order of minutes and achieved high PC3 tumor inhibition at $0.2 \mathrm{mg} \cdot \mathrm{kg}^{-1}$ doses. ${ }^{165,167}$ Advance of both nitroprusside $\left[\mathrm{Fe}(\mathrm{NO})(\mathrm{CN})_{5}\right]^{2-}$ to phase I clinical trial against several cancers and leiomyoma as an anti-angiogenic drug, and of Oxacom as an hypotensive drug against endometriosis, highlighted the therapeutic promise of iron complexes for NO 
delivery. ${ }^{168,169}$ Furthermore, DNIC showed high potential for sensitizing hypoxic cells to $\gamma$-radiation damage ${ }^{170}$ or to chemotherapeutics, ${ }^{171}$ thus offering opportunities in combination with adjuvant therapies.

\section{Conclusions and Perspectives}

Overall, significant developments in the field of metallodrugs, and especially anticancer iron complexes, were achieved recently with growing emphasis on studying their behavior and mechanism of action at the cellular level. As a matter of fact, the examples discussed in this perspective illustrate the variety in structures of molecular iron complexes that were screened for anticancer applications, ranging from non-heme iron complexes, photoactive and bio-inspired iron complexes. Those showed elevated anticancer activities with $\mathrm{IC}_{50}$ down to the nanomolar range on a broad range of cancer cell lines, hence offering opportunities for the treatment of both solid and soft tumors, which contrasts with the reference platinum-based chemotherapies that are limited to the treatment of solid tumors. Another beneficial aspect of iron complexes for biomedical application lies in their negligible effects on non-cancerous cells and overall elevated safety index that foresees a safer use and significant progress in cancer management for patients.

The wide applicability of iron complexes can probably be explained by the diversity in cellular effects that were observed both in vitro and in vivo, since such molecular complexes can interfere with the maintenance of intracellular redox balance, disturb iron homeostasis, intercalate in DNA and so forth. Considering the redox activity of iron complexes in biological environment and their affinity for thiols and selenols that are abundant in proteins and enzymes, it is of paramount importance to screen for metabolization pathways. Hence, metabolites can be more active than their parent compounds, and overlooking this aspect can lead to misconception in the design of libraries of drug candidates that ultimately leads to a dead end. In this context, we emphasize the importance of rationalizing the structure-activity relationship and uncovering the active species. While carrying such study on cells and living systems can be both lengthy and pricey, and often results in a bottleneck, a recent work by Gasser et al. described a good alternative for in vitro screening of the behavior of metal complexes in plasma or microsomes to mimic blood and liver conditions. ${ }^{172}$ Moreover, the wide array of mechanisms of action and targets observed for iron complexes drug candidates highlights the difficulty of a compelling investigation due to the complex biological environment and their intertwined pathways. The case of iron complexes is especially complicated due to the presence of elevated levels of endogenous iron that, on one hand make it difficult to quantify the uptake of the iron complex, and on the other hand can lead to cross-talk with endogenous iron and disturbance of the iron homeostasis in the case of labile complexes. Such lock out will be a key point to leverage in order to facilitate the investigation of iron complexes and other metal-based therapeutics in living systems, and to this end progress in the neighboring fields of speciation by metallomic study, ${ }^{173,174}$ sub-cellular imaging ${ }^{175,176}$ and bioinformatics ${ }^{177}$ will be of essential.

While increasing knowledge in the cellular effects and behavior of iron complexes is welcome, in the near future it will be important for the field to investigate their mechanism of action via an interdisciplinary approach, bringing together bioinorganic and theoretical chemists, cellular biologists, bioinformaticians, and specialists in medical imaging. The synergy between those neighbor fields appears to us as a key element to acquire in-depth knowledge in their cellular effects, as exemplified by the groundbreaking progress in the comprehension of cellular effects of ferrocifens that fastened their pre-clinical investigation in view of evaluation in clinical trials. Hence, we anticipate growing collaborative work in the near future to contribute in unveiling the richness in therapeutic opportunities offered by iron complexes as anticancer drug candidates, and we expect this will stimulate further translational studies to establish a new paradigm in cancer treatment.

\section{Abbreviations}

${ }^{1} \mathrm{O}_{2}$ Singlet oxygen

A2780 Human ovarian cancer

A549 Human lung cancer

AFM-IR Atomic force microscopy

AKT Signal transduction pathway that promotes cells' survival and growth

BDF1 Bromodomain-containing factor 1 gene

bp Base pair

BLM Bleomycin

BSA Bovine serum albumin

BT474 Human breast cancer

C57BL/6 Inbred strain of laboratory mouse

CAM Chorioallantoic membranes

Caski Human cervical cancer

CCD-19Lu Normal human lung fibroblast

CCRF-CEM Human lymphoblastic leukemia

CDK2 Cyclin-dependent kinase 2

CT-26 Colon cancer

DNIC Dinitrosyl iron complexes

dpa Dipicolylamines

dpq Dipyridoquinoxalines

ESCC Esophageal squamous cell carcinoma

FDA Food and drug administration

GSH Glutathione

H322 Human lung cancer

HDAC Histone deacetylase

HeLa Human cervical cancer

HUVEC Human umbilical vein endothelial cells

ICP-OES Inductively coupled plasma with optical emission spectrometry

IR infra-red spectroscopy

JAHA Jay Amin hydroxamic acid

JNK Proliferation signaling pathway

Jurkat Human T-cell leukemia 
L1210 Mouse lymphocytic leukemia

LD50 Median lethal dose

LIP Labile iron pool

LMCT Ligand-to-metal charge-transfer

MAPK Proliferation signaling pathway

MC Metal centered state

MCF10A Human epithelial mammary gland

MCF7 Human breast cancer

MDA-MB-231 Human breast cancer

MLCT metal to ligand charge-transfer state

MPK Pathway that regulates cellular response to DNA damage NHDF Normal Human Dermal Fibroblasts

nM Nanomolar concentration

p38 Mitogene

p53 Tumor suppressor gene

PARP Poly (ADP-ribose) polymerase

PBS Phosphate buffer saline

PC Photochemotherapy

PDT Photodynamic therapy

PET Positron emission tomography

phen Phenanthroline

poly (dA) polydeoxyadenylic acid

poly(dT) polydeoxythymidylic acid

poly $(\mathrm{dC})$ polydeoxycytidylic acid

poly $(\mathrm{dG})$ polydeoxyguanylic acid

PS Photosensitizers

py5-OH 2,6-bis[hydroxybis(2-pyridyl)methyl]pyridine

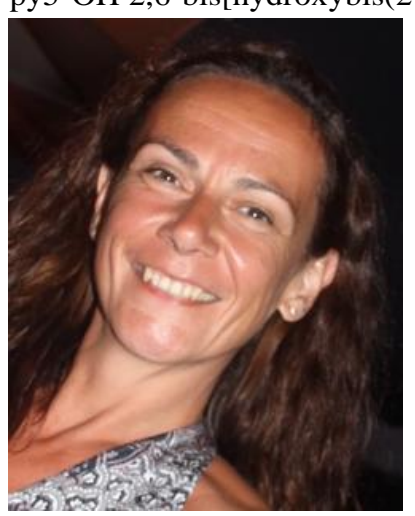

QM Quinone methide

qqy Quinquepyridine

ROS Reactive oxygen species

SA- $\beta$-gal Senescence-associated

$\beta$-galactosidase

SAHA Suberoylanilide

hydroxamic acid

salen

$\mathrm{N}, \mathrm{N}-$

bis(salicylidene)ethylenediamin

salophen

$\mathrm{N}, \mathrm{N}-$

bis(salicylidene)phenylenediami

ne

SK-Mel28 Human melanoma

SMS-KCNR Human neuroblastoma

SOD Superoxide dismutase

TfR Transferrin receptor

TNF- $\alpha$ Tumor necrosis factor- $\alpha$

tpy Terpyridine

TSC Thiosemicarbazones

TRAIL TNF- related apoptosis- inducing ligand

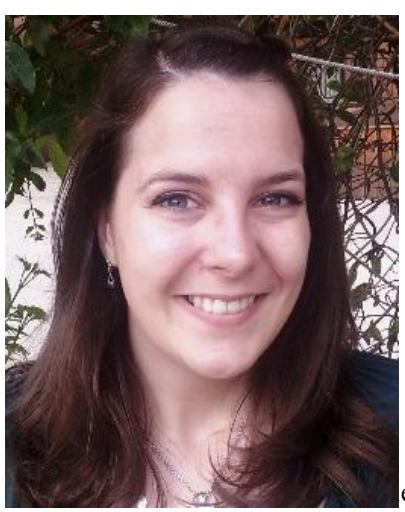

TrxR Thioredoxin reductase

U87 Human gioblastoma

VX2 Rabbit neoplasm

ZR-75-1 Human breast cancer

$\mu \mathrm{M}$ Micromolar concentration

Mathilde Bouché received her PhD from the University of Strasbourg (France) in 2017,

ety of Chemistry 20xx where she specialized in bioinorganic chemistry and platinum anticancer candidates stabilized with $N$-heterocyclic carbenes. Then, she was awarded a Fulbright postdoctoral fellowship to pursue her research on the development of biomaterials for drug delivery and medical imaging at the University of Pennsylvania (U.S.). More recently, she joined the University of Lorraine (France) as a postdoctoral fellow. Her current research interests encompass functional iron complexes for anticancer therapy and investigation of their cellular effects to unveil their mechanism of action. She is the author of 18 scientific publications and book chapter and 1 patent.

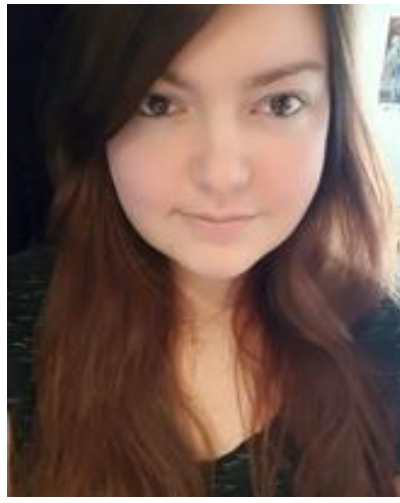

Cécilia Hognon is a second year PhD student at the LPCT department of the University of Lorraine Nancy (France). She is interested in studying DNA lesion induction and their repair processes in different organisms including humans and bacteria. She is also focusing on the comprehension of epigenetics processes at DNA level and on the effects of orgnamotellic complexes on such regulations. To this aim she uses theoretical chemistry machinery especially molecular dynamics, free energy calculations, and hybrid QM/MM techniques.

Stéphanie Grandemange, after her Ph.D in 2005 obtained at University of Montpellier II, France, she has worked in Martinou's Lab, Geneva, Schwizerland from 2005 to 2008. Since 2008, she is associate professor at University of Lorraine in CRAN laboratory. She has worked on the involvement of mitochondria in tumorigenesis and relations between mitochondrial dynamics and cellular stresses. Presently, her work is focused on cancer cell biology and particularly in the identification of new tumorigenic markers as well as new therapeutical anticancer strategies. She has notably studied the protein Damaged DNA Binding 2 (DDB2) in breast cancer cells and demonstrated its involvement in transcriptional regulation of target genes. Her work also concerns the study of the transcriptional regulation of DDB2 that involved an indirect methylation process and try to define new therapeutic agents able to modulate gene expression and fight cancer. She has co-supervised $6 \mathrm{PhDs}$. She is author of about 40 publications.

Antonio Monari received his Ph.D. from the University of Bologna, Italy, in 2007 and is presently associate professor at

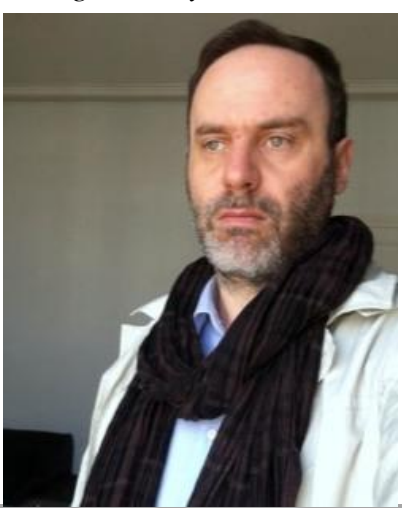
the LPCT department of the University of Lorraine and CNRS in Nancy, France. He is interested in the development and use of multiscale methods, including $Q M / M M$ and nonadiabatic dynamics, to study 
photophysical and photochemical phenomena taking place in complex (biological) environments. He is also interested in describing the structural and dynamical behavior of complex biological architectures submitted to external stress sources via enhanced sampling molecular dynamics and free energy techniques. He particularly tackles DNA photolesions induction and repair, the photosensitization of other biological systems, such as vision related proteins, and the photophysics of organometallic compounds. He is author of more than 150 publications and is member of the executive committee of the French Society of Photobiology, and of the CNRS "Comité National" for the physical chemistry and numerical methods in biology sections.

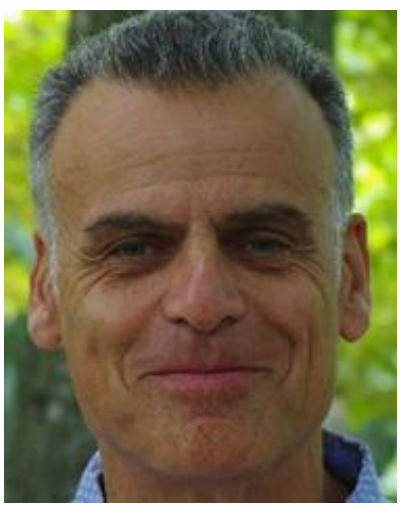

Philippe C. Gros received his $\mathrm{PhD}$ in Organic Chemistry from the university of Lyon (France) in 1992. He is presently first-class CNRS Research Director and Head of the L2CM, a 70 members joint CNRS \& University of Lorraine Laboratory in Nancy (France). He is the author of about 120 international research papers. His research interests encompass the design of organometallic reagents for functionalization of heterocycles, ligand synthesis, and the design of transition metal complexes with applications various fields such as solar energy and biology.

\section{Conflicts of interest}

The authors declare no competing interest.

\section{Acknowledgements}

Support from the Université de Lorraine and CNRS is gratefully acknowledged. The authors wish to thank the Université de Lorraine LUE i-site program for funding under the Mirabelle+ program.

\section{Notes and references}

${ }^{1}$ I. S. Um, E. Armstrong-Gordon, Y. E. Moussa, D. Gnjidic and N. J. Wheate, Inorg. Chim. Acta, 2019, 492, 177-181.

${ }^{2}$ M. C. Apps, E. H. Y. Choi and N. J. Wheate, Endocr. Relat. Cancer, 2015, 22, 219-233.
${ }^{3}$ R. Oun, Y. E. Moussa and N. J. Wheate, Dalton Trans., 2018, 47, 6645-6653.

${ }^{4}$ D. M. Cheff and M. D. Hall, J. Med. Chem., 2017, 60, 45174532.

${ }^{5}$ E. Alessio, Eur. J. Inorg., 2017, 12, 1549-1560.

${ }^{6}$ E. Boros, P. J. Dyson and G. Gasser, Chem., 2020, 6, 41-60.

${ }^{7}$ R. G. Kenny and C. J. Marmion, Chem. Rev., 2019, 119, 1058-1137.

${ }^{8}$ M. Mora, M. C. Gimeno and R. Visbal, Chem. Soc. Rev., 2019, 48, 447-462.

9 Y. C. Ong and G. Gasser, Today Technol., 2020, 10.1016/j.ddtec.2019.06.001

${ }^{10}$ S. Bellemin-Laponnaz, Eur. J. Inorg. Chem., 2020, 1, 1020.

${ }^{11}$ M. Wenzel and A. Casini, Coord. Chem. Rev., 2017, 352, 432-460.

12 Y. Wang, H. Li and H. Sun, Inorg. Chem., 2019, 58, 13673-13685.

13 E. C. Sutton, C. E. McDevitt, M. V. Yglesias, R. M. Cunningham and V. J. DeRose, Inorg. Chim. Acta, 2019, 498, 118984

${ }^{14}$ A. Singh, I. Lumb, V. Mehra and V. Kumar, Dalton Trans., 2019, 48, 2840-2860.

${ }^{15}$ R. Wang, H. Chen, W. Yan, M. Zheng, T. Zhang and Y. Zhang, Eur. J. Med. Chem., 2020, 190, 112109.

${ }^{16}$ U. Basu, M. Roy, A. R. Chakravarty, Coord. Chem. Rev., 2020, 417, 213339.

${ }^{17}$ W. A. Wani, U. Baig, S. Shreaz, R. A. Shiekh, P. F. Iqbal, E. Jameel, A. Ahmad, S. H. Mohd-Setapar, M. Mushtaque and L. T. Hun, New J. Chem., 2016, 40, 1063-1090.

${ }^{18}$ A. Pöthig and A. Casini, Theranostics, 2019, 9, 3150-3169.

${ }^{19}$ D. Astruc, Eur. J. Inorg. Chem., 2017, 1, 6-29.

${ }^{20}$ M. Patra and G. Gasser, Nat. Rev. Chem., 2017, 1, 0066.

${ }^{21}$ M. Navarro, W. Castro and C. Biot, Organometallics, 2012, 31, 5715-5727.

22 A. Kondratskyi, K. Kondratska, F. V. Abeele, D. Gordienko, C. Dubois, R.A. Toillon, C. Slomianny, S. Lemière, P. Delcourt, E. Dewailly, R. Skryma, C. Biot and N. Prevarskaya, Sci. Rep., 2017, 7, 15896.

23 K. Kowalski, Coord. Chem. Rev., 2018, 366, 91-108.

${ }^{24}$ D. L. Bertuzzi, G. Perli, C. B. Braga, C. Ornelas, New J. Chem., 2020, 44, 4694-4703.

${ }^{25}$ D. Osella, M. Ferrali, P. Zanello, F. Laschi,M. Fontani, C. Nervi and G. Cavigiolio, Inorg. Chim. Acta, 2000, 306, $42-$ 48.

26 S. Galadari, A. Rahman, S. Pallichankandy and F. Thayyullathil, Free Radic. Biol. Med., 2017, 104, 144-164.

${ }^{27}$ Q. Cui, J.-Q. Wang, Y. G. Assaraf, L. Ren, P. Gupta, L. Wei, C. R. Ashby Jr, D.-H. Yang and Z.-S. Chen, Drug Resist. Updat., 2018, 41, 1-25.

28 P. Davalli, T. Mitic, A. Caporali, A. Lauriola and D. D’Arca, Oxid. Med. Cell Longev., 2016, 3565127. 
${ }^{29}$ F. Zhao, C. Zhao and Z.-Q. Liu, J. Biol. Inorg. Chem. 2011, 16, 1169-1176.

${ }^{30}$ A. Vessières, C. Corbet, J. M. Heldt, N. Lories, N. Jouy, I. Laïos, G. Leclercq, G. Jaouen and R.-A. Toillon, J. Inorg. Biochem., 2010, 104, 503-511.

31 W. A. Wlassoff, C. D. Albright, M. S. Sivashinski, A. Ivanova, J. G. Appelbaum and R. I. Salganik, J. Pharm. Pharmacol., 2007, 59, 1549-1553.

${ }^{32}$ H. Skoupilova, M. Bartosik, L. Sommerova, J. Pinkas, T. Vaculovic, V. Kanicky, J. Karban, R. Hrstka, Eur. J.

Pharmacol., 2020, 867, 172825.

${ }^{33}$ W. Chen, W. Ou, L. Wang, Y. Hao, J. Cheng, J. Li and Y.N. Liu, Dalton Trans., 2013, 42, 15678-15686.

${ }^{34}$ K. Kowalski, P. Hikisz, L. Szczupak, B. Therrien and A. Koceva- Chyła, Eur. J. Med. Chem., 2014, 81, 289-300.

${ }^{35}$ Y. Li, H. Ma, L. Han, W. Liu, B. Zhao, S. Zhang and J. Miao, Acta Pharmacol. Sin., 2013, 34, 960-968.

${ }^{36}$ H. Zhou, M. Li, J. Qu, S. Jing, H. Xu, J. Zhao, J. Zhang and M. He, Organometallics, 2016, 35, 1866-1875.

${ }^{37}$ S. Shen, J. Shao, J. Luo, J. Liu, J. Miao and B. Zhao, Eur. J. Med. Chem., 2013, 63, 256-268.

${ }^{38}$ W. Daher, L. Pelinski, S. Klieber, F. Sadoun, V. Meunier, M. Bourrié, C. Biot, F. Guillou, G. Fabre, J. Brocard, L. Fraisse, J.-P. Maffrand, J. Khalife and D. Dive, Drug Metab. Dispos., 2006, 34, 667-682.

${ }^{39}$ C. Supan, G. Mombo-Ngoma, M. P. Dal-Bianco, C. L. O. Salazar, S. Issifou, F. Mazuir, A. Filali-Ansary, C. Biot, D. Ter-Minassian, M. Ramharter, P. G. Kremsner and B. Lell, Antimicrob. Agents Chemother., 2012, 46, 3165-3173.

${ }^{40}$ P. Kopf- Maier, H. Kopf and E. W. Neuse, Angew. Chem. Int. Ed. Engl., 1984, 23, 456-457.

${ }^{41}$ R. Kovjazin, T. Eldar, M. Patya, A. Vanichkin, H. M. Lander, A. Novogrodsky, FASEB J., 2003, 17, 467-469.

${ }^{42}$ G. Jaouen, A. Vessières and S. Top, Chem. Soc. Rev., 2015, 44, 8802-8817.

${ }^{43}$ C. Bruyère, V. Mathieu, A. Vessières, P. Pigeon, S. Top, G. Jaouen and R. Kiss, J. Inorg. Biochem., 2014, 141, 144-151.

${ }^{44}$ F. Tonolo, M. Salmain, V. Scalcon, S. Top, P. Pigeon, A. Folda, B. Caron, M. J. McGlinchey, R.-A. Toillo, A. Bindoli, G. Jaouen, A. Vessières and M. P. Rigobello, ChemMedChem., 2019, 14, 1717-1726.

${ }^{45}$ H. Z. S. Lee, O. Buriez, F. Chau, E. Labbé, R. Ganguly, C. Amatore, G. Jaouen, A. Vessières, W. K. Leong and S. Top, Eur. J. Inorg. Chem., 2015, 25, 4217-4226.

${ }^{46}$ Y. Wang, P. Pigeon, S. Top, M. J. McGlinchey and G. Jaouen, Angew. Chem. Int. Ed. Engl., 2015, 54, 10230-10233.

${ }^{47}$ Y. L. K. Tan, P. Pigeon, E. A. Hillard, S. Top, M.-A. Plamont, A. Vessières, M. J. McGlinchey, H. Müller-Bunz and G. Jaouen, Dalton Trans., 2009, 10871-10881.

48 D. Hamels, P. M. Dansette, E. A. Hillard, S. Top, A. Vessières, P. Herson, G. Jaouen and D. Mansuy, Chem. Int. Ed. Engl., 2009, 48, 9124-9126.
49 J. Zhang, X. Li, X. Han, R. Liu and J. Fang, Trends Pharmacol. Sci., 2017, 38, 794-808.

${ }^{50}$ J. Zhang, B. Zhang, X. Li, X. Han, R. Liu and J. Fang, Med. Res. Rev., 2019, 39, 5-39.

51 A. Citta, A. Folda, A. Bindoli, P. Pigeon, S. Top, A. Vessières, M. Salmain, G. Jaouen and M. P. Rigobello, J. Med. Chem., 2014, 57, 8849-8859.

52 A. C. de Oliveira, E. G. da Silva, D. D. Rocha, E. A. Hillard, P. Pigeon, G. Jaouen, F. A. R. Rodrigues, F. C. de Abreu, F. R. Ferreira, M. O. F. Goulart and L. Costa-Lotufo, ChemMedChem, 2014, 9, 2580-2586.

${ }^{53}$ D.-G. Jia, J.-A. Zheng, Y.-R. Fan, J.-Q. Yu, X.-L. Wu, B.-J. Wang, X.-B. Yang and Y. Huang, J. Organometallic. Chem., 2019, 888, 16-23.

54 S. Fery-Forgues, B. Delavaux-Nicot, J. Photochem. Photobiol A: ChemI, 2000, 132, 137-159.

${ }^{55}$ S. Hostachy, C. Policar and N. Delsuc, Coord. Chem. Rev., 2017, 351, 172-188.

${ }^{56}$ D. Lin, T. Gong, Z.-Y. Hong, S. Qiu, J. Pan, C.-Y. Tseng, S. Feng, R. Chen and K. V. Kong, Anal. Chem., 2018, 90, 7139-7147.

${ }^{57}$ E. B. Bauer, A. A. Haase, R. M. Reich, D. C. Crans and F. E. Kühn, Coord. Chem. Rev., 2019, 393, 79-117.

${ }^{58}$ Y. Wang, F. Heinemann, S. Top, A. Dazzi, C. Policar, L. Henry, F. Lambert, G. Jaouen, M. Salmain and A. Vessieres, Dalton Trans., 2018, 47, 9824-9833.

59 B. Schechter, G. Caldwell and E. W. Neuse, J. Inorg. Organomet. P., 2000, 10, 177-188.

${ }^{60}$ E. Allard, C. Passirani, E. Garcion, P. Pigeon, A. Vessières, G. Jaouen, J.-P. Benoit, J. Control. Rel., 2008, 130, 146-153.

${ }^{61}$ A.-L. Lainé, E. Adriaenssens, A. Vessières, G. Jaouen, C. Corbet, E. Desruelles, P. Pigeon, R.-A. Toillon and C. Passirani, Biomaterials, 2013, 34, 6949-6956.

62 A.-L. Lainé, A. Clavreul, A. Rousseau, C. Tétaud, A. Vessieres, E. Garcion, G. Jaouen, L. Aubert, M. Guilbert, J.P. Benoit, R.-A. Toillon and C. Passirani, Nanomed. Nanotechnol., 2014, 10, 1667-1677.

${ }^{63}$ P. Resnier, N. Galopin, Y. Sibiril, A. Clavreul, J. Cayon, A. Briganti, P. Legras, A. Vessières, T. Montier, G. Jaouen, J.-P. Benoit and C. Passirani, Pharm. Res., 2017, 126, 54-65.

${ }^{64}$ J. Toms, V. Reshetnikov, S. Maschauer, A. Mokhir and O. Prante, J. Labelled Comp. Rad., 2018, 61, 1081-1088.

${ }^{65}$ J. Spencer, J. Amin, M. Wang, G. Packham, S. S. S. Alwi, G. J. Tizzard, S. J. Coles, R. M. Paranal, J. E. Bradner, T. D. Heightman, ACS Med. Chem. Lett., 2011, 2 , 358-362.

${ }^{66}$ M. Librizzi, A. Longo, R. Chiarelli, J. Amin, J. Spencer and C. Luparello, Chem. Res. Toxicol., 2012, 25, 2608-2616.

${ }^{67}$ J. Spencer, J. Amin, R. Boddiboyena, G. Packham, B. E. Cavell, S. S. S. Alwi, R. M. Paranal, T. D. Heightman, M. Wang, B. Marsden, P. Coxhead, M. Guille, G. J. Tizzard, S. J. Coles and J. E. Bradner, Med. Chem. Commun., 2012, 3, 6164. 
68 C. Tang, Y. Du, Q. Liang, Z. Cheng, J. Tian, Organometallics, 2018, 37, 2368-2375.

69 H. Hagen, P. Marzenell, E. Jentzsch, F. Wenz, M. R. Veldwijk and A. Mokhir, J. Med. Chem., 2012, 55, 924-934.

${ }^{70}$ F. Gao, F. Wang, X. Nie, Z. Zhang, G. Chen, L. Xia, L.-H. Wang, C.-H. Wang, Z.-Y. Hao, W.-J. Zhang, C.-Y. Hong and Y.-Z. You, New J. Chem., 2020, 44, 3478-3486.

${ }^{71}$ P. Marzenell, H. Hagen, L. Sellner, T. Zenz, R. Grinyte, V. Pavlov, S. Daum and A. Mokhir, J. Med. Chem., 2013, 56, 6935-6944.

72 A. Leonidova, P. Anstaett, V. Pierroz, C. Mari, B. Spingler, S. Ferrari and G. Gasser, Inorg Chem, 2015, 54, 9740-9748.

73 S. Daum, S. Babiy, H. Konovalova, W. Hofer, A. Shtemenko, N. Shtemenko, C. Janko, C. Alexiou and A. Mokhir, J. Inorg. Biochem., 2018, 178, 9-17

74 S. Daum, J. Toms, V. Reshetnikov, H. G. Özkan, F. Hampel, S. Maschauer, A. Hakimioun, F. Beierlein, L. Sellner, M. Schmitt, O. Prante and A. Mokhir, Bioconjug. Chem., 2019, 30, 1077-1086.

75 V. Reshetnikov, S. Daum, C. Janko, W. Karawacka, R. Tietze, C. Alexiou, S. Paryzhak, T. Dumych, R. Bilyy, P. Tripal, B. Schmid, R. Palmisano, A. Mokhir, Angew. Chem. Int. Ed. Engl., 2018, 57, 11943-11946.

${ }^{76}$ S. Daum, M. S. V. Reshetnikov, M. Sisa, T. Dumych, M. D. Lootsik, R. Bilyy, E. Bila, C. Janko, C. Alexiou, M. Herrmann, L. Sellner and A. Mokhir, Angew. Chem. Int. Ed. Engl., 2017, 56, 15545-15549.

${ }^{77}$ S. Daum, V. F. Chekhun, I. N Todor, N. Y. Lukianova, Y. V. Shvets, L. Sellner, K. Putzker, J. Lewis, T. Zenz, I. A.M. de Graaf, G. M. M. Groothuis, A. Casini, O. Zozulia, F. Hampel, A. Mokhir, J. Med. Chem., 2015, 58, 2015-2024.

${ }^{78}$ T. S. Morais, A. Valente, A. I. Tomaz, F. Marques, M. H. Garcia, Future Med. Chem., 2016, 8, 527-544.

79 D. Rocco, L. K. Batchelor, E. Ferretti, S. Zacchini, G. Pampaloni, P. J. Dyson, F. Marchetti, ChemPlusChem, 2020, 85, 110-122.

${ }^{80}$ A. Pilon, P. Gírio, G. Nogueira, F. Avecilla, H. Adams, J. Lorenzo, M. H. Garcia and A. Valente, J. Organomet. Chem., 2017, 852, 34-42.

${ }^{81}$ A. Cingolani, V. Zanotti, S. Zacchini, M. Massi, P. V. Simpson, N. M. Desai, I. Casari, M. Falasca, L. Rigamonti and R. Mazzoni, Appl. Organomet. Chem., 2019, 33, e4779.

${ }^{82}$ M. Jakubaszek, B. Goud, S. Ferrari and G. Gasser, Chem. Commun., 2018, 54, 13040-13059.

${ }^{83}$ J. Li, T. Chen, Coord. Chem. Rev., 2020, 418, 213355.

${ }^{84}$ S. A. McFarland, A. Mandel, R. Dumoulin-White and G. Gasser, Curr. Opin. Chem. Biol., 2019, 56, 23-27.

${ }^{85}$ R. Siebert, A. Winter, B. Dietzek, U. S. Schubert and J. Popp, Macromol.r Rapid Commun., 2010, 31, 883-888.

86 M. Roy, S. Saha, A. K. Patra, M. Nethaji and A. R. Chakravarty, Inorg. Chem., 2007, 46, 4368-4370.
87 U. Basu, I. Khan, A. Hussain, P. Kondaiah and A. R. Chakravarty, Angew. Chem. Int. Ed. Engl., 2012, 51, 26582661.

${ }^{88}$ A. Garai, I. Pant, P. Kondaiah and A. R. Chakravarty, Polyhedron, 2015, 102, 668-676.

89 U. Basu, I. Pant, A. Hussain, P. Kondaiah and A. R. Chakravarty, Inorg. Chem., 2015, 54, 3748-3758.

90 U. Basu, I. Khan, A. Hussain, P. Kondaiah, A. R. Chakravarty, Angew. Chem. Int. Ed., 2012, 51, 2658-2661.

${ }^{91}$ U. Basu, I. Pant, P. Kondaiah and A. R. Chakravarty, Eur. J. Inorg. Chem., 2016, 2016, 1002-1012.

${ }^{92}$ T. Sarkar, A. Bhattacharyya, S. Banerjee, A. Hussain, Chem. Commun., 2020, 56, 7981-7984.

${ }^{93}$ A. Garai, I. Pant, A. Bhattacharyya, P. Kondaiah and A. R. Chakravarty, Chemistry Select, 2017, 2, 11686-11692.

94 A. Garai, A. Gandhi, V. Ramu, M. K. Raza, P. Kondaiah and A. R. Chakravarty, ACS Omega, 2018, 3, 9333-9338.

${ }^{95}$ S. Sahoo, S. Podder, A. Garai, S. Majumdar, N. Mukherjee, U. Basu, D. Nandi and A. R. Chakravarty, Eur. J. Inorg. Chem., 2018, 2018, 1522-1532.

${ }^{96}$ S. Saha, R. Majumdar, A. Hussain, R. R. Dighe and A. R. Chakravarty, Philos. Trans. A Math. Phys. Eng Sci, 2013, 371, 20120190.

${ }^{97}$ T. Duchanois, L. Liu, M. Pastore, A. Monari, C. Cebrián, Y. Trolez, M. Darari, K. Magra, A. Francés-Monerris, E. Domenichini, M. Beley, X. Assfeld, S. Haacke and P. C. Gros, Inorganics, 2018, 6, 63.

${ }^{98}$ L. Liu, T. Duchanois, T. Etienne, A. Monari, M. Beley, X. Assfeld, S. Haacke and P. C. Gros, Phys. Chem. Chem. Phys., 2016, 18, 12550-12556.

${ }^{99}$ J. Karges, P. Goldner and G. Gasser, Inorganics, 2019, 7, 4. 100 J. Karges, G. Gasser, Inorg.a Chim. Acta, 2020, 499, 119196.

${ }^{101}$ W.-L. Kwong, C.-N. Lok, C.-W. Tse, E. L.-M. Wong and C.-M. Che, Chemistry, 2015, 21, 3062-3072.

${ }^{102}$ E. L.-M. Wong, G.-S. Fang, C.-M. Che and N. Zhu, Chem. Commun., 2005, 4578-4580.

103 O. Singh, N. Tyagi, M. M. Olmstead and K. Ghosh, Dalton Trans., 2017, 46, 14186-14191.

${ }^{104}$ J. Chen, Z. Luo, Z. Zhao, L. Xie, W. Zheng and T. Chen, Biomaterials, 2015, 71, 168-177.

${ }^{105}$ H. Lai, X. Zhang, P. Feng, L. Xie, J. Chen and T. Chen, Chem. Asian J., 2017, 12, 982-987.

${ }^{106}$ H. Lin, Y. Wang, H. Lai, X. Li and T. Chen, Chem. Asian J., 2018, 13, 2730-2738.

${ }^{107}$ L. Xie, Z. Luo, Z. Zhao and T. Chen, J. Med. Chem., 2017, 60, 202-214.

${ }_{108}$ J. Ye, J. Ma, C. Liu, J. Huang, L. Wang and X. Zhong, Biochem. Pharmacol., 2019, 166, 93-107.

109 H. Zhu, C. Dai, L. He, A. Xu and T. Chen, Front. Pharmacol., 2019, 10, 946. 
110 T. Duchanois, T. Etienne, M. Beley, X. Assfeld, E. A. Perpète, A. Monari and P. C. Gros, Eur. J. Inorg. Chem., 2014, 2014, 3747-3753.

${ }^{111}$ U. Basu, I. Khan, D. Koley, S. Saha, P. Kondaiah and A. R. Chakravarty, J. Inorg. Biochem., 2012, 116, 77-87.

112 H. Gattuso, T. Duchanois, V. Besancenot, C. Barbieux, X. Assfeld, P. Becuwe, P. C. Gros, S. Grandemange and A. Monari, Front. Chem., 2015, 3, 67.

113 H. Gattuso, V. Besancenot, S. Grandemange, M. Marazzi and A. Monari, Sci. Rep., 2016, 6, 28480.

${ }^{114}$ A. Francés-Monerris, M. Lineros-Rosa, M. A. Miranda, V. Lhiaubet-Vallet and A. Monari, Chem. Commun., 2020, 56, 4404-4407.

${ }^{115}$ A. Erxleben, Inorg. Chim. Acta, 2018, 472, 40-57.

${ }^{116}$ G. Baráth, J. Kaizer, G. Speier, L. Párkányi, E. Kuzmann and A. Vértes, Chem. Commun., 2009, 3630-3632.

117 A. Hille, I. Ott, A. Kitanovic, I. Kitanovic, H. Alborzinia, E. Lederer, S. Wölfl, N. Metzler-Nolte, S. Schäfer, W. S. Sheldrick, C. Bischof, U. Schatzschneider and R. Gust, J. Biol. Inorg. Chem., 2009, 14, 711-725.

${ }^{118}$ A. Silvestri, G. Barone, G. Ruisi, M. T. Lo Giudice and S. Tumminello, J. Inorg. Biochem., 2004, 98, 589-594.

119 R. Herchel, Z. Šindelář, Z. Trávníček, R. Zbořil and J. Vančo, Dalton Trans., 2009, 9870-9880.

${ }^{120}$ S. El Deeb, B. N. Ma and R. Gust, J. Sep. Sci., 2012, 35, 3434-3438.

121 J. Vančo, Z. Šindelář, Z. Dvořák and Z. Trávníček, J. Inorg. Biochem., 2015, 142, 92-100.

${ }^{122}$ T. S. Lange, K. K. Kim, R. K. Singh, R. M. Strongin, C. K. McCourt and L. Brard, PLoS ONE, 2008, 3, e2303.

${ }^{123}$ K. K. Kim, R. K. Singh, R. M. Strongin, R. G. Moore, L. Brard and T. S. Lange, PLoS ONE, 2011, 6, e19049.

124 J. Sagasser, B. N. Ma, D. Baecker, S. Salcher, M. Hermann, J. Lamprecht, S. Angerer, P. Obexer, B. Kircher and R. Gust, J. Med. Chem., 2019, 62, 8053-8061.

125 D. Baecker, B. N. Ma, J. Sagasser, L. Schultz, C. Hörschläger, M. Weinreich, L. Steiner, B. Kircher and R. Gust, Dalton Trans., 2020, 49, 6842-6853.

${ }^{126}$ M. Umemura, Md. R. Islam, H. Fukumura, I. Sato, Y. Kawabata, K. Matsuo, R. Nakakaji, A. Nagasako, M. Ohtake, F. Takayuki, U. Yokoyama, T. Nakayama, H. Eguchi and Y. Ishikawa, Cancer Sci., 2019, 110, 356-365.

${ }^{127}$ X. Huang, Mutat. Res.-Fund. Mol. M., 2003, 533, 153-171.

${ }^{128}$ P. Heffeter, V. F. S. Pape, É. A. Enyedy, B. K. Keppler, G. Szakacs and C. R. Kowol, Antioxid. Redox Signal., 2019, 30, 1062-1082.

129 D. R. Richardson, Curr. Med. Chem., 2005, 12, 27112729.

${ }^{130}$ D. R. Richardson, D. S. Kalinowski, S. Lau, P. J. Jansson and D. B. Lovejoy, Biochim. Biophys. Acta, 2009, 1790, 702717.
131 D. R. Richardson, P. C. Sharpe, D. B. Lovejoy, D. Senaratne, D. S. Kalinowski, M. Islam and P. V. Bernhardt, $J$. Med. Chem., 2006, 49, 6510-6521.

${ }^{132}$ W. P. Sohtun, T. Khamrang, A. Kannan, G. Balakrishnan, D. Saravanan, M. A. Akhbarsha, M. Velusamy and M. Palaniandavar, Appl. Organomet. Chem., 2020, 34, e5593.

${ }^{133}$ B. Kaya, Z. K. Yılmaz, O. Şahin, B. Aslim, Ü. Tükenmez and B. Ülküseven, J. Biol. Inorg. Chem., 2019, 24, 365-376.

134 J.-C. Lee, K.-C. Chiang, T.-H. Feng, Y.-J. Chen, S.-T. Chuang, K.-H. Tsui, L.-C. Chung and H.-H. Juang, Int. J. Mol. Sci., 2016, 17, 1435.

135 K. Pelivan, W. Miklos, S. van Schoonhoven, G. Koellensperger, L. Gille, W. Berger, P. Heffeter, C. R. Kowol and B. K. Keppler, J. Inorg. Biochem., 2016, 160, 61-69.

${ }^{136}$ A. Santoro, B. Vileno, Ò. Palacios, M. D. Peris-Díaz, G. Riegel, C. Gaiddon, A. Krężel and P. Faller, Metallomics, 2019, 11, 994-1004.

${ }^{137}$ J. Shao, B. Zhou, A. J. Di Bilio, L. Zhu, T. Wang, C. Qi, J. Shih and Y. Yen, Mol. Cancer Ther., 2006, 5, 586-592.

138 R. S. Moussa, Z. Kovacevic and D. R. Richardson, Oncotarget, 2015, 6, 29694-29711.

139 R. S. Moussa, K. C. Park, Z. Kovacevic and D. R. Richardson, Free Radic. Biol. Med., 2019, 133, 276-294.

${ }^{140}$ J. Zhou, Y. Jiang, J. Zhao, H. Zhang, J. Fu, P. Luo, Y. Ma, D. Zou, H. Gao, J. Hu, Y. Zhang and Z. Jing, Cell Oncol., 2020, 43, 461-475.

141 J. J. Knox, S. J. Hotte, C. Kollmannsberger, E. Winquist, B. Fisher and E. A. Eisenhauer, Invest. New Drugs, 2007, 25, 471-477.

${ }^{142}$ I. Gojo, M. L. Tidwell, J. Greer, N. Takebe, K. Seiter, M. F. Pochron, B. Johnson, M. Sznol and J. E. Karp, Leuk. Res., 2007, 31, 1165-1173.

${ }^{143}$ M. Horinaka, T. Yoshida, T. Shiraishi, S. Nakata, M. Wakada, R. Nakanishi, H. Nishino, H. Matsui and T. Sakai, Oncogene, 2005, 24, 7180-7189.

144 A. Versini, L. Colombeau, A. Hienzsch, C. Gaillet, P. Retailleau, S. Debieu, S. Müller, T. Cañeque and R. Rodriguez, Chemistry - A European Journal, 2020, 26, 74167424.

${ }^{145}$ G. Csire, L. Canabady-Rochelle, M.-C. Averlant-Petit, K. Selmeczi and L. Stefan, Metallomics, 2020, DOI:10.1039/D0MT00103A.

146 V. Della Latta, A. Cecchettini, S. Del Ry and M. A. Morales, Pharmacol. Res., 2015, 97, 122-130.

147 H. Umezawa, T. Takita, Y. Sugiura, M. Otsuka, S. Kobayashi and M. Ohno, Tetrahedron, 1984, 40, 501-509.

${ }^{148}$ L. V. Liu, C. B. Bell, S. D. Wong, S. A. Wilson, Y. Kwak, M. S. Chow, J. Zhao, K. O. Hodgson, B. Hedman and E. I. Solomon, Proc. Natl. Acad. Sci. U.S.A., 2010, 107, 2241922424 .

149 R. M. Burger, V. M. Grigoryants and C. P. Scholes, Dalton Trans., 2017, 46, 13263-13272. 
${ }^{150}$ K. Ray, F. F. Pfaff, B. Wang and W. Nam, J. Am. Chem. Soc., 2014, 136, 13942-13958.

151 F. Carrascoza, M. Surducan, L. A. Eriksson and R. Silaghi-Dumitrescu, Inorg. Chim. Acta, 2020, 509, 119682.

152 J. Biya, A. Stoclin, S. Dury, J. Le Pavec, O. Mir, J. Lazarovici, C. Fermé, M. Annereau, K. Ekpe, C. Massard and J.-M. Michot, Bull. Cancer, 2016, 103, 651-661.

${ }^{153}$ R. A. Watson, H. De La Peña, M. T. Tsakok, J. Joseph, S. Stoneham, J. Shamash, J. Joffe, D. Mazhar, Z. Traill, L.-P. Ho, S. Brand and A. S. Protheroe, Br. J. Cancer, 2018, 119, 1044-1051.

${ }^{154}$ D. Fukumura, S. Kashiwagi and R. K. Jain, Nat. Rev. Cancer, 2006, 6, 521-534.

${ }^{155}$ L. Liu, M. Xu-Welliver, S. Kanugula and A. E. Pegg, Cancer Res., 2002, 62, 3037-3043.

156 N. Schneiderhan, A. Budde, Y. Zhang and B. Brüne, Oncogene, 2003, 22, 2857-2868.

${ }^{157}$ H.-Y. Hsiao, C.-W. Chung, J. H. Santos, O. B. Villaflores and T.-T. Lu, Dalton Trans., 2019, 48, 9431-9453.

${ }^{158}$ T.-T. Lu, Y.-M. Wang, C.-H. Hung, S.-J. Chiou and W.-F. Liaw, Inorg. Chem., 2018, 57, 12425-12443.

${ }^{159}$ C.-K. Chiang, K.-T. Chu, C.-C. Lin, S.-R. Xie, Y.-C. Liu, S. Demeshko, G.-H. Lee, F. Meyer, M.-L. Tsai, M.-H. Chiang and C.-M. Lee, J. Am. Chem. Soc., 2020, 142, 8649-8661.

${ }^{160}$ H.-C. Huang, W.-M. Ching, Y.-T. Tseng, C.-H. Chen and T.-T. Lu, Dalton Trans., 2019, 48, 5897-5902.

${ }^{161}$ C. E. Schiewer, C. S. Müller, S. Dechert, M. Bergner, J. A. Wolny, V. Schünemann and F. Meyer, Inorg. Chem., 2019, 58, 769-784.

${ }^{162}$ R. Pulukkody, R. B. Chupik, S. K. Montalvo, S. Khan, N. Bhuvanesh, S.-M. Lim and M. Y. Darensbourg, Chem. Commun., 2017, 53, 1180-1183.

163 T. N. Rudneva, O. S. Zhukova, G. V. Shilov, I. O. Chikileva, M. V. Kisilevskii, N. A. Sanina and S. M. Aldoshin, J. Coord. Chem., 2019, 72, 972-986.

${ }_{164}$ N. Sanina, N. Shmatko, T. Stupina, A. Balakina and A. Terent'ev, Molecules, 2017, 22, 1426.

${ }^{165}$ S.-C. Wu, C.-Y. Lu, Y.-L. Chen, F.-C. Lo, T.-Y. Wang, Y.-J. Chen, S.-S. Yuan, W.-F. Liaw and Y.-M. Wang, Inorg. Chem., 2016, 55, 9383-9392.

${ }^{166}$ P.-H. Liu, F.-T. Tsai, B.-H. Chen, I.-J. Hsu, H.-H. Hsieh and W.-F. Liaw, Dalton Trans., 2019, 48, 6040-6050.

${ }^{167}$ D. C. Pectol, S. Khan, R. B. Chupik, M. Elsabahy, K. L. Wooley, M. Y. Darensbourg and S.-M. Lim, Mol. Pharmaceutics, 2019, 16, 3178-3187.

168 E. I. Chazov, O. V. Rodnenkov, A. V. Zorin, V. L. Lakomkin, V. V. Gramovich, O. N. Vyborov, A. G. Dragnev, C. A. C. A. Timoshin, L. I. Buryachkovskaya, A. A. Abramov, V. P. Massenko, E. V. Arzamastsev, V. I. Kapelko and A. F. Vanin, Bull. Exp. Biol. Med., 2012, 26, 148-156.
169 E. N. Burgova, Y. I. Khristidis, A. V. Kurkov, V. D. Mikoyan, A. B. Shekhter, L. V. Adamyan, P. S. Timashev and A. F. Vanin, Cell Biochem. Biophys., 2019, 77, 69-77.

${ }^{170}$ J. B. Mitchell, D. A. Wink, W. DeGraff, J. Gamson, L. K. Keefer and M. C. Krishna, Cancer Res., 1993, 53, 58455848.

${ }^{171}$ Y.-C. Sung, P.-R. Jin, L.-A. Chu, F.-F. Hsu, M.-R. Wang, C.-C. Chang, S.-J. Chiou, J. T. Qiu, D.-Y. Gao, C.-C. Lin, Y.S. Chen, Y.-C. Hsu, J. Wang, F.-N. Wang, P.-L. Yu, A.-S. Chiang, A. Y.-T. Wu, J. J.-S. Ko, C. P.-K. Lai, T.-T. Lu and Y. Chen, Nat. Nanotechnol., 2019, 14, 1160-1169.

${ }^{172}$ S. Keller, Y. C. Ong, Y. Lin, K. Cariou and G. Gasser, J.Organomet. Chem., 2020, 906, 121059.

${ }^{173}$ A. R. Timerbaev, K. Pawlak, C. Gabbiani and L. Messori, TrAC Trend. Anal. Chem., 2011, 30, 1120-1138.

${ }^{174}$ Y. Wang, H. Wang, H. Li and H. Sun, Dalton Trans., 2014, 44, 437-447.

175 J. Decelle, G. Veronesi, B. Gallet, H. Stryhanyuk, P. Benettoni, M. Schmidt, R. Tucoulou, M. Passarelli, S. Bohic, P. Clode and N. Musat, Trend. Cell. Biol., 2020, 30, 173-188. ${ }^{176} \mathrm{H}$. Li and H. Sun, Metallomics, 2014, 6, 69-76.

${ }^{177}$ E. Dumont and A. Monari, Front. Chem., 2015, 3, 43. 